\title{
The Therapeutic Potential of Pomegranate and Its Products for Prevention of Cancer
}

\author{
Arzu Akpinar-Bayizit, Tulay Ozcan and Lutfiye Yilmaz-Ersan \\ Uludag University \\ Turkey
}

\section{Introduction}

Pomegranate (Punica granatum L.) is considered one of the oldest known edible fruits and is the symbolic of abundance and prosperity. For thousand of years, many cultures have believed that pomegranate have beneficiary effects on health, fertility, longevity and rebirth. The recent interest for this fruit is not only because of the pleasant taste, but also due to the scientific evidences that suggest therapeutic activity such as anti-atherogenic, antiparasitic, antimicrobial, antioxidant, anticarcinogenic and antiinflammatory effects. These beneficial effects were attributed to the antioxidative properties of pomegranate phenolic compounds, tannins and anthocyanins as well as other phytochemicals. The constituents of pomegranate have been thoroughly investigated, however, clinical trials are in progress to explore the therapeutic potential of pomegranate products, particularly determining preventive efficacy of pomegranate extracts in cancer, cardiovascular diseases, inflammation, diabetes and ultraviolet radiation-induced skin damage. In order to facilitate the further investigations the information contained in this work is based upon the immense work on impact of administration of pomegranate extracts, particularly in cancer prevention such as skin, prostate, breast, and colon.

\section{The constituents of pomegranate and derived products}

Along with olives, figs and grapes, pomegranates are among the first plants to have been cultivated by man. Pomegranate (Punica granatum L.) is considered one of the oldest known edible fruit that is mentioned in the Koran, the Bible, the Jewish Torah, and the Babylonian Talmud as 'Food of Gods' that is symbolic of plentyness, fertility and prosperity (Madihassan, 1984; Aviram et al., 2000; Seeram et al., 2006). The pomegranate, a mystical and highly distinctive fruit, is the predominant member of two species comprising the Punicaceae family. The genus name Punica, was the Roman name for Carthage, where the best pomegranates were known to grow. Pomegranate is known by the French as grenade, the Spanish as granada (derived from the ancient city of Granada), and literally translates to seeded ("granatus") apple ("ponium") (Jurenka, 2008).

In ancient Greek mythology, the edible part of pomegranate known as the "fruit of the dead", containing considerable amounts of saccharides, polyphenol, and available in Hades for its residents. Hades benefitted amorously when six pomegranate seeds from his kingdom sealed for him the betrothal of the daughter of Zeus and Demeter. The 
Babylonians regarded the seeds as an agent of resurrection, the Persians as conferring invincibility on the battle field and for ancient Chinese alchemical adepts; the bright red juice was mythopoetically regarded as a "soul concentrate", a synonym to human blood, conferring to longevity and immortality (Dahham et al., 2010). Since ancient times, the pomegranate has been used extensively in the folk medicine of many cultures as a "healing food" in order to eliminate parasites, as an antihelmintic and vermifuge, antipyretic, and to treat and cure aphtae, ulcers, diarrhea, acidosis, dysentery, hemorrhage, microbial infections, and respiratory pathologies. It also features prominently in the ceremonies, art, and mythology of the Egyptians and Greeks, and was the personal emblem of Maximilian, the Holy Roman Emperor (Longtin, 2003; Larrosa et al., 2010; Lee et al., 2010).

The pomegranate fruit is round, with leathery skin or rind, typically yellow, overlaid with light or deep pink or rich red. The edible part of the fruit, the arils can be preserved as syrup or used for juice, jam, jelly, wine, vinegar, and fruit leather production, and can be an alternative to flavoring and coloring used in beverages (Maestre et al., 2000; Fadavi et al., 2005; Ozgen et al., 2008; Al-Said et al., 2009; Mousavinejad et al., 2009; Akbarpour et al., 2010).

\subsection{Chemical composition of pomegranates}

The pomegranate tree can be divided into several anatomical compartments: seed, juice, peel, leaf, flower and root bark, each of which is widely used in therapeutic and food formulas, and cosmetics due in large part to the scientifically supported health benefits on arteriosclerosis, cholesterol levels and cancer prevention. The other parts are good source of tannins, dyes, and alkaloids (Khan, 2009; Viuda-Martos et al., 2010; Wang et al., 2010). The chemical composition of the pomegranate and its products depends on the cultivar, growing region, and climate, the fruit's stage of maturity, cultural practices and manufacturing systems (Badenes et al., 1998; Dumas et al., 2003; Toor et al., 2006; Raffo et al., 2006, Borochov-Neori et al., 2009; Zarei et al., 2011). Tables 1 \& 2 show the chemical composition of pomegranate fruit and phytochemicals in pomegranate and its parts.

\begin{tabular}{|l|l|}
\hline Constituent & $72.6-86.4 \%$ \\
\hline Moisture & $0.05-1.6 \%$ \\
\hline Protein & $0.01-0.9 \%$ \\
\hline Fat & $0.36-0.73 \%$ \\
\hline Mineral elements & $3.4-5.0 \%$ \\
\hline Fibre & $15.4-19.6 \%$ \\
\hline Carbohydrates & $3.0-12.0 \mathrm{mg}$ \\
\hline Calcium & $8.0-37.0 \mathrm{mg}$ \\
\hline Phosphorus & $0.3-1.2 \mathrm{mg}$ \\
\hline Iron & $3.0 \mathrm{mg}$ \\
\hline Sodium & $9.0 \mathrm{mg}$ \\
\hline Magnesium & $4.0-14.0 \mathrm{mg}$ \\
\hline Ascorbic acid (Vitamin C) & $0.01 \mathrm{mg}$ \\
\hline Thiamine (Vitamin $\left.\mathrm{B}_{1}\right)$ & $0.012-0.03 \mathrm{mg}$ \\
\hline Riboflavine (Vitamin $\left.\mathrm{B}_{2}\right)$ & $0.18-0.3 \mathrm{mg}$ \\
\hline Niacine &
\end{tabular}

*Values per $100 \mathrm{~g}$ of edible portions

Table 1. Chemical Composition of Pomegranate* (Yilmaz, 2007). 


\begin{tabular}{|l|l|}
\hline Plant Component & Constituents \\
\hline Pomegranate juice & $\begin{array}{l}\text { Anthocyanins; glucose; ascorbic acid; phenolics such as } \\
\text { ellagic acid, gallic acid, caffeic acid, catechin, } \\
\text { epigallocatechin gallate (EGCG), quercetin, rutin; } \\
\text { mineral elements; aminoacids }\end{array}$ \\
\hline $\begin{array}{l}\text { Pomegranate seed oil } \\
\text { Pomegranate pericarp (peel, }\end{array}$ & $\begin{array}{l}\text { Punicic acid; ellagic acid; fatty acids; sterols } \\
\text { Phenolic compounds like punicalagins, gallic acid, } \\
\text { catechin, EGCG, quercetin, rutin, anthocyanidins, other } \\
\text { flavonoids }\end{array}$ \\
\hline Pomegranate leaves & $\begin{array}{l}\text { Ellagitannins (punicalin and punicafolin); flavonols such } \\
\text { as luteolin and apgenin }\end{array}$ \\
\hline Pomegranate flower & $\begin{array}{l}\text { Gallic acid, triterpenoids such as ursolic,maslinic and } \\
\text { asiatic acid }\end{array}$ \\
\hline Pomegranate roots and bark & Ellagitannins; piperidine alkaloids
\end{tabular}

Table 2. Phytochemicals of Pomegranate (Jurenka, 2008).

About $50 \%$ of the total fruit weight corresponds to the peel, which is an important source of bioactive compounds such as phenolics, flavonoids, ellagitannins (ETs), and proanthocyanidin compounds (Li et al., 2006), minerals (Mirdehghan \& Rahemi, 2007), and complex polysaccharides (Jahfar et al., 2003). Significant variations in organic acids, phenolic compounds, sugars, water-soluble vitamins, and minerals of pomegranates have been reported by various researchers (Davidson et al., 2009; Tezcan et al., 2009).

The edible part of the pomegranate fruit consists of $40 \%$ arils and $10 \%$ seeds. The arils are comprised of approximately $80 \%$ juice and $20 \%$ seed. The juice of arils contain $85 \%$ water, $10 \%$ total sugars (glucose, sucrose, and fructose) (Melgarejo \& Artes, 2000), and 1.5\% pectin, organic acids (citric, malic, tartaric, succinic, fumaric, ascorbic acid) (Tezcan et al., 2009), fatty acids (i.e. conjugated linoleic acid, linoleic acid, punicic acid and eleostearic acid) (Fadavi et al., 2006) and amino acids (i.e. proline, valin, and methionine) (Seppi \& Franciosi, 1980), and bioactive compounds (phenolics and flavonoids) (Dahham et al., 2010). Pomegranate fruit is a rich source of two types of polyphenolic compounds: anthocyanins and hydrolyzable tannins, which account for $92 \%$ of the antioxidant activity of the whole fruit (Gil et al., 2000). The soluble polyphenol content in pomegranate juice varies between 0.2 and $1.0 \%$ depending on variety (Narr Ben et al., 1996). The seeds are a rich source of lipids; of which comprised to $12 \%$ to $20 \%$ of total seed weight and characterized by a high content of polyunsaturated (n-3) fatty acids such as linolenic, linoleic, and other lipids such as punicic acid, oleic acid, stearic acid, and palmitic acid (Ozgul-Yucel, 2005). The seeds also contain protein, crude fibers, vitamins, minerals, pectin, sugars, polyphenols, isoflavones (mainly genistein), the phytoestrogen coumestrol, and the sex steroid, estrone (Singh et al., 1990; Singh \& Sethi, 2003; El-Nemr et al., 2006; Syed et al., 2007).

Pomegranate flowers (gulnar) contain a variety of secondary metabolites: i) polyphenols, including gallic acid (Huang et al., 2005b), ellagic acid and ethyl brevifolin-carboxylate (Wang et al., 2006), and ii) triterpene acids consisting of oleanolic, ursolic (Huang et al., 2005a), maslinic and asiatic (Batta \& Rangaswami, 1973). In folk medicine the decoction of flowers is used to stop bleeding and purging (Sivarajan \& Balachandran, 1994; Jafri et al., 
2000). The polyphenols in pomegranate flowers have strong antioxidant activity (Oswa et al., 1987); ellagic acid had a marked inhibitory effect on the occurrence and development of tumours in mice (Boukharta et al., 1992), triterpenes show antimutagenic and anticarcinogenic effects (Ovesná et al., 2004); and oleanolic acid significantly enhanced acute glucose-stimulated insulin secretion at basal and stimulatory glucose concentrations in pancreatic b-cell, and such effects may contribute to the antidiabetic properties (Teodoro et al., 2008).

Pomegranate fruit extracts/constituents possesses immense biological activities such as anticarcinogenic (Whitley et al., 2003; Afaq et al., 2005), antibacterial (Akiyama et al., 2001; Prashanth et al., 2001; Duman et al., 2009), antidiarrhoeal (Das et al., 1999), antifungal (Dutta et al., 1998), antiulcer (Gharzouli et al., 1999), antioxidant activity and free radical scavenging capability (Schubert et al., 1999; Aviram et al., 2000; Festa et al., 2001), strengthening of the immune system (Lee et al., 2008), prevention of heart disease (Johanningsmeier \& Harris, 2011) and liver fibrosis (Thresiamma \& Kuttan, 1996), and inhibition of lipid peroxidation even at lower concentrations than vitamin E (Rosenblat et al., 2003). All these therapeutical activities are related to the presence of diverse 'phenolic compounds', including gallic acid, protocatechinunic acid, chlorogenic acid, caffeic acid, ferulic acid, coumaric acid, and catechin and hydrolysable tannins (such as punicalin, pedunculagin, punicalagin, corilagin, casuarinin, punicacortein, granatin and ellagic acid), and anthocyanins (delphinidin, cyanidin and pelargonidin 3-glucosides and 3,5diglucosides) (Amakura et al., 2000; Noda et al., 2002; Poyrazoglu et al., 2002; Kulkarni \& Aradya, 2005; Viuda-Martos et al., 2010).

The bright colour of pomegranate flowers and arils is due to anthocyanins (Afaq et al., 2005); however, only one anthocyanin compound (i.e. pelargonidin-3,5-diglucoside) has yet been identified in pomegranate flowers using HPLC (Miguel et al., 2009), whereas in pomegranate juice, principally cyanidin-3-O-glucoside, cyanidin-3,5-di-O-glucoside, delphinidin-3-O-glucoside, delphinidin-3,5-di-Oglucoside, pelargonidin-3-O-glucoside, and pelargonidin-3,5-di- O-glucoside, have been reported (Lansky \& Newman 2007; Jaiswal et al., 2010).

Tannins, high-molecular-weight plant polyphenols, are divided into 3 chemically and biologically distinct groups: condensed tannins or proanthocyanidins, hydrolyzable tannins or elagitannins (ETs), and gallotannins (GTs) (Seeram et al., 2005). Pomegranate leaves contain unique tannins such as punicalin and punicafolin, and also have glycosides of apigenin, a flavone with progestinic (Zand et al., 2000) and anxiolytic (Paladini et al., 1999) properties. Pomegranate peel are rich in hydrolyzable tannins, mainly punicalin, pedunculagin, and punicalagin (Seeram et al., 2006), which differ from proanthocyanidins in their chemical structures. In addition to ETs, pomegranate peel contains hydroxybenzoic acids such as gallagic, ergot alkaloid (EA), and EA glycosides (Amakura et al., 2000); anthocyanidins are principally cyanidin, pelargonidin, and delphinidin (Noda et al., 2002) and flavonoids such as kaempferol, luteolin, and quercetin (Van Elswijk et al., 2004).

Al-Maiman \& Ahmad (2002) showed the amounts of potassium, calcium and sodium were highest in both juice and seeds followed by magnesium, phosphorous, zinc, iron and copper. The authors stated that pomegranate can be a good source of nutrients and variation could originate from the pomegranate cultivar, and agro-climatic. Akpinar-Bayizit (2010) reported that although processing steps include clarification and filtration, the pomegranate 
juices in Turkish market were a good source for minerals such as potassium $(1283.30 \mathrm{mg} / \mathrm{L})$, calcium (107.53 mg/L), sodium $(96.02 \mathrm{mg} / \mathrm{L})$, phosphorus $(76.54 \mathrm{mg} / \mathrm{L})$ and magnesium $(67.22 \mathrm{mg} / \mathrm{L})$. The high mineral content of pomegranate juices could contribute to the daily intake of these constituents in the human diet.

\subsection{Pomegranate fruit derived products}

Pomegranate can be consumed as fresh, fruit juice, fermented fruit juice, dried aril, frozen aril, minimally-processed aril, canned aril, jam, jelly, wine, vinegar, paste, fruit leather and in flavoring products.

Pomegranate arils can either be consumed fresh or procesed (dried, frozen, canned and minimally-processed). The conventional utilization of wild pomegranate fruit lies in the drying seeds along with pulp (arils), which constitute a traditional product called as 'Anardana' (Pruthi \& Saxena, 1984). The dehydrated arils are acidic (7.8-15.4\%), help in improving mouth-feel and digestion, and are widely used as acidulent in culinary preparations. The dried anardana contains acid (5.8-15.4\%), total sugars $(9.3-17.5 \%)$ and crude fiber as compared to fresh fruit. To obtain frozen arils the arils are put into polyethylene bags either with syrup of $15^{\circ}$ Brix or coated with solid sugar and frozen in a chest freezer. For canned arils, used generally as an appartiser, the arils were put into metal tins with syrup of $15^{\circ}$ Brix and sterilised for 10 minutes. In the production of minimallyprocessed pomegranate aril pomegranates are chilled to $0^{\circ} \mathrm{C}$, selected, washed and dried with a current of air at room temperature. They are conditioned in polyethylene bags that were heat-sealed and conserved in a chamber at $0^{\circ} \mathrm{C}$ for $10-15$ days. These arils are used as a garnish for desserts and salad (Al-Maiman \& Ahmad, 2002).

Pomegranate juice can be extracted by using a spiral-type screw press without crushing the seeds. The juice is clarified by heating in a flash pasteurizer at $79-82^{\circ} \mathrm{C}$ cooling, settled for 24 hours and filtered. The clear juice can be preserved by heat treatment or by using chemicals. The use of sulphur dioxide is banned for pomegranate due to loss of colour by bleaching action of $\mathrm{SO}_{2}$. Pomegranate juice represents one of the foods recently promoted for its health benefits since a glass of pomegranate juice contains about $40 \%$ of the Recommended Daily Allowance (RDA) of Vitamin C (Singh \& Singh, 2004).

Pomegrenate syrup of $60^{\circ}$ Brix with an added acidity of $1.5 \%$ as citric acid has a bright purplish-red colour and a delightful taste and flavour. It was preserved by pasteurization. Preparation of jelly on a small-scale from sweet-sour pomegranates is described by Adsule et al. (1992) and Singh \& Singh (2004). When making the jellies, approximately $50 \%$ of the total anthocyanins present in the juice of are lost. During storage at $5^{\circ} \mathrm{C}$, certain colour differences were observed, which indicates that the $\mathrm{pH}$ was not the only parameter responsible for this characteristic.

For preparation of wine, the whole furits are pressed without crushing or juice may be extracted from pomegranate grains, which gives a yield of 76 to 85\% (Adsule \& Patil, 1995). Sugar is added to the juice to obtain $22-23^{\circ}$ Brix. The juice is fermented as in the same manner of red grape wine. The wine is flash pasteurized at $60^{\circ} \mathrm{C}$ and bottled hot (Singh \& Singh, 2004).

Pomegranate seed is a residue obtained from pomegranate juice production, ranging between 40 and $100 \mathrm{~g} / \mathrm{kg}$ of fruit weight (Fadavi et al., 2006; Lansky \& Newman, 2007). The 
seeds are rich source of lipids, and the fatty acid component of pomegranate seed oil comprises over $95 \%$ of the oil, of which $99 \%$ is triacylglycerols. Minor components of the oil include vitamin E, sterols, steroids, and a key component of mammalian myelin sheaths, cerebroside (Tsuyuki et al., 1981).

'Pekmez', a concentrated and shelf-life extended Turkish product, is generally produced from fruits containing high amounts of sugar such as grape, mulberry, carnob, apple, pomegranate, plum and apricot (Alparslan \& Hayta, 2002; Demirozu et al., 2002). The first steps in pomegranate pekmez production is washing, granulating and crushing of the pomegranates. The pomegranate juice, obtained by pressing the crushed pomegranates by a pneumatical or mechanical press, is boiled with a calcareous substance called 'pekmez earth', white soil containing $70.40 \% \mathrm{CaCO}_{3}$ or technical $\mathrm{CaCO}_{3}$, for deacidification and neutralization. The juice is clarified and concentrated usually in open vessels, and rarely under vacuum at $565 \mathrm{~mm} \mathrm{Hg}$ and $66^{\circ} \mathrm{C}$, up to $65-68^{\circ}$ Brix; this product is called 'liquid pekmez'. The liquid pekmez can be consumed either as liquid or solidified at $6^{\circ} \mathrm{C}$ for $2-3$ days via addition of hydrocolloids, to produce 'solid pekmez', which has a pasty form that is easily spread on a slice of bread.

The 'pomegranate leather (pestil)' is another Turkish pomegranate derived product that can be stored for a long time without deterioration. Pomegranates are washed, granulated, crushed, pressed and filtered to separate the seeds and skin. Pekmez earth is added to neutralize and clarify the fresh pomegranate juice. Clarified juice is filtered and is mixed with the wheat starch. Nuts such as walnut or hazelnut can be added in small pieces if desired. The juice and starch mixture is concentrated upto $40^{\circ}$ Brix by boiling and continuous stirring. The puree is spread on cloths of $0.5-2.00 \mathrm{~mm}$ thickness and sun-dried until a mild, tasty, light and chewable leathery product is obtained. The dried pestil is folded, cut and stored in dry conditions (Maskan et al., 2002).

The 'pomegranate molasses (sour pomegranate pekmez, nar eksisi, pomegranate sauce)', a traditional seasoning commonly used in salads and many dishes to improve the taste and aroma characteristics in Turkey, is a concentrated product produced simply by boiling, without the addition of further sugar or other additives (Poyrazoglu et al., 2002; Incedayi et al., 2010). Pomegranate molasses is a highly nutritive product since it is more concentrate and the have a high mineral content. Traditional methods are still being used to produce pomegranate molasses, of which requires cleaning, crushing, extraction, filtration, and evaporation (upto $35-65^{\circ}$ Brix) in an open vessel or under vacuum. Clarification is not recommended in pomegranate molasses since customers prefer bitterness and sourness that comes from phenolic substances and acidity (Vardin \& Abbasoglu, 2004; Kaya \& Sozer, 2005).

\section{The biochemistry and pharmokinetics of pomegranate}

There is little knowledge about the absorption, bioavailability, biodistribution, and metabolism of the bioactive compounds present in pomegranate and in other fruits, although they probably have a similar pathway (Petti \& Scully, 2009). The bioavailability of polyphenols varies according to the structure, glycosylation and solubility of the molecules which defined their extractability (Lecerf, 2006; Ozcan et al., 2011). In view of limited human studies, it appears that the bioavailability determinations of pomegranate polyphenols is 
affected by individual variability, differential processing of pomegranate juice, and the analytical techniques used, which need to be sensitive enough to detect low postprandial concentrations of these metabolites (Basu \& Penugonda, 2009). An in vitro study of pomegranate juice showed that phenolic compounds are available during the digestion in a quite high amount $(29 \%)$, however, due to $\mathrm{pH}$, anthocyanins are in large transformed into non-red forms and/or degraded and similar results are obtained for vitamin C (PérezVicente et al., 2002).

The recent interest in pomegranate products is due to the fruit's beneficial role in the prevention of prostate cancer, the prevention of the oxidation of both low density lipoprotein (LDL), high density lipoprotein (HDL), and cholesterol, reductions in blood pressure, arthritis, anemia, diarrhea, inflammation, gynecological diseases, atherosclerosis development, the stimulation of T-cell functions and production of cytokines, Alzheimer's disease, and improvoment of sperm quality (Figure 1). These beneficial effects were attributed to the wide range of phytochemicals found in pomegranate. These phytochemicals are predominantly phenolic compounds as well as to those of sugarcontaining polyphenolic tannins and anthocyanins, including primarily hydrolysable ellagitannins, anthocyanins and other polyphenols. Gil et al. (2000) have demonstrated that one of the ellagitannins, punicalagins, is responsible for over $50 \%$ of the antioxidant activity of the pomegranate juice. The same reserachers indicated that as being water-soluble, commercial pomegranate juice obtained by pressing the fruit contain significant amounts of punicalagins, depending on the cultivar. Seeram et al. (2005) proposed punicalagin as a proper chemical marker for the authentication, quality control and standardization of pomegranate products.

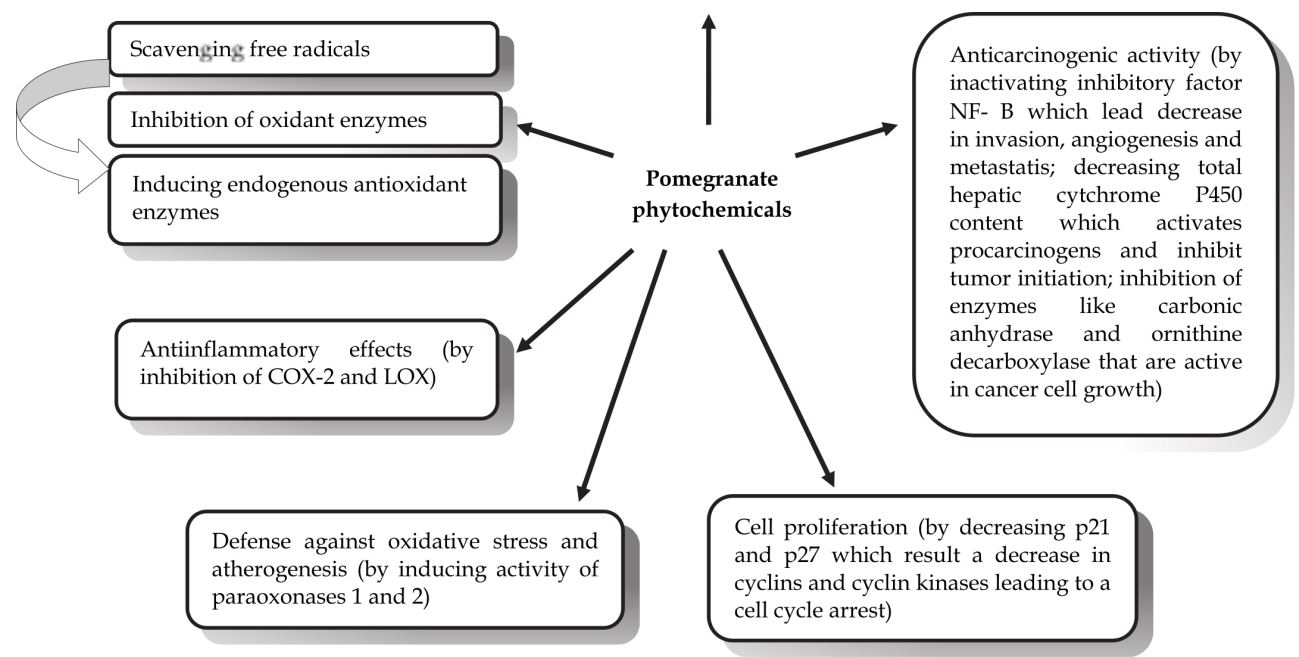

Fig. 1. Bioactive effects of pomegranate constituents.

\section{The health benefits of pomegranate derived products}

In recent years, the focus is on understanding the mechanisms of nutraceutic and health promoting potentials of the foods nutrients. Cancer, in terms of morbidity and mortality, is a 
major health issue, eventhough there are advances in early detection and in treatment options. Cancer is an aggressive disease, which if not detected at an early stage can metastasize to other organs of the body. Carcinogenesis (cancer development) is a multistage process, influenced by mainly age, dietary habits and hormonal balance. There are three stages of cancer: initiation, promotion and progression (Surh, 2003). The hypothesis of alternative methods to prevent cancer seems to be practical and promising strategy to reduce cancer incidinces since treatment options for metastasized cancers remain inadequate. Chemoprevention focuses on cancer prevention by the administration of one or more synthetic or naturally occurring agents to suppress reverse or prolong the process of carcinogenesis (Mukhtar \& Ahmad, 1999).

It is clear that bioactive compounds present in daily diet, mainly in fruits and vegetables, have prevention potential in cancer by inhibiting carcinogenesis through cell-defensive and cell-death mechanism regulation. These chemopreventive effects may be attributed to a complex effect of various phenolic substances of antioxidant capacity (Khan et al., 2008).

Pomegranate is rich in anthocyanins, 3-glucosides, 3,5-diglucosides of delphinidin, cyanidin and pelargonidin, ellagitannins and other phenolic compounds, which are known bioactive compounds with antioxidant and antitumoral activity (Ozgen et al., 2008; Chaturvedula et al., 2011; Zhang et al., 2011). Major hydrolysable tannins in pomegranates are gallotannins, ellagic acid tannins and gallagyl tannins, generally termed as punicalagins, and they have been shown to inhibit the proliferation of human cancer cells and modulate inflammatory subcellular signaling pathways due to a high antioxidant activity (Seeram et al., 2005).

There are several studies conducted to evaluate the efficacy of pomegranate and its products as an anti-proliferative, anti-invasive, and pro-apoptotic agent in various cancer cell lines such as skin, prostate, breast, column, and blood cancer. Adams et al. (2006) revealed that pomegranate juice suppresses cancer activity through the combined antioxidant and antiinflammatory effects by modulating inflammatory cell signaling in colon cancer cells. Malik et al. (2005) suggested that pomegranate juice may have cancer chemopreventive as well as cancer-chemotherapeutic effects against prostate cancer in humans. Pomegranate fruit extract possesses remarkable antitumor-promoting effects in mouse skin.

Researchers found that daily consumption of pomegranate juice may improve stressinduced myocardial ischemia in patients who have coronary heart disease (CHD) and the pomegranate juice not only prevented hardening of the arteries by reducing blood vessel damage, but also reversed the progression of CHD (Sumner et al., 2005). Hartman et al. (2006) reported that pomegranate juice had beneficial effect on animal model of Alzheimer's disease since polyphenols are responsible for neural protection.

\subsection{Antioxidant activity}

Over the past few years, consumer demand-based research on functional foods gave a basis for traditional using of pomegranate, which lead to an increase in number of scientific papers concerning pomegranate and its products with health-improving effects (Mehta \& Lansky, 2004; Rettig et al., 2008; Turk et al., 2008; Alam et al., 2010; Dai et al., 2010; Jadeja et al., 2010; Park et al., 2010). The reports have focused on in vitro, ex vivo, and in vivo antioxidant actions, of pomegranate and its products, which are attributed to the chemical composition. However, many other cellular processes are likely to be involved along with 
bioactive compounds to enhance reactive oxygen species (ROS) elimination and inhibit ROS generation. Oxidative stress, refers to a cell state characterized by excessive production of ROS, has been given growing attention, as the generation of ROS, thus improved oxidative stress, can induce DNA damage and trigger redox-dependent transcription factors which lead to cancer, inflammatory, cardiovascular and neurodegenerative diseases, and aging (Evans et al., 2004; Franco et al., 2008; Ziech et al., 2010; Sedelnikova et al., 2010; Kryston et al., 2011; Martin et al., 2011). Nishikawa (2008) mentioned that sublethal levels of ROS can induce additional changes in DNA of tumor cells to make those cells malignant, stimulate the proliferation of cancer cells, and activate the expression of various molecules, some of which assist cancer cells to form metastatic colonies.

The effect of pomegranate cultivars on antioxidant activity was target of study by some authors (Borochov-Neori et al., 2009; Mousavinejad et al., 2009; Pande \& Akoh, 2009; Sadeghi et al. 2009). All authors reported considerable variation in some of the chemical composition profile (lipids, phenols, organic acids, vitamins, sugars) and antioxidant properties of pomegranate samples, independent on the antioxidant method performed. The antioxidant activity of pomegranate and its products was almost determined via in vitro trials and several methods could be used for its determination, however, pomegranate showed an antioxidant activity, independent on the antioxidant test assayed and generally with significant linear correlation between phenolic content and antioxidant capacity (Elfalleh et al., 2009). Seeram et al. (2005) stated that the antioxidant level in pomegranate juice was higher than found in other fruit juices, such as blueberry, cranberry, and orange. Schubert et al. (1999) and Gil et al. (2000) demonstrated that pomegranate juice and seed extracts have 2-3 times the in vitro antioxidant capacity of either red wine or green tea.

Rosenblat et al. (2006) have shown that pomegranate extracts scavenge free radicals, and decrease macrophage oxidative stress and lipid peroxidation in animals. Studies in rats and mice confirmed the antioxidant properties of a pomegranate by-product extract made from whole fruit minus the juice, showing a 19\% reduction in oxidative stress in mouse peritoneal macrophages (MPMs), a $42 \%$ decrease in cellular lipid peroxide content, and a $53 \%$ increase in reduced glutathione levels. A study in rats with chemically induced liver damage demonstrated that pretreatment with a methanolic extract of pomegranate peel enhanced or maintained the free-radical scavenging activity of the hepatic enzymes such as catalase, peroxidase, and superoxide dismutase to values comparable with control values, whereas resulted in $54 \%$ reduction of lipid peroxidation values compared to controls (Chidambara Murthy et al., 2002).

Using the FRAP (ferric reducing/antioxidant power) assay, Guo et al. (2008) found that consumption of $250 \mathrm{~mL}$ pomegranate pulp juice daily for four weeks by healthy elderly subjects resulted in increased plasma antioxidant capacity, while subjects consuming apple juice experienced no significant increase. In addition, subjects consuming the pomegranate pulp juice exhibited significantly decreased plasma carbonyl content, a biomarker for oxidant/antioxidant barrier impairment in various inflammatory diseases.

Several works have demonstrated that peel, seeds, arils have antioxidant activity, nevertheless, after ingestion those antioxidant compounds, mainly tannin components, are metabolized by gut bacteria into urolithins, which readily enter systemic circulation. Bialonska et al. (2009a) studied the antioxidant activities of seven urolithins derivatives in a 
cell-based assay in order to reflect bioavailability of the test compound to the cells, and the antioxidant activity is evaluated in the cellular environment and in terms of inhibition of intracellular generation of reactive oxygen species. They found that urolithins exhibited a significant antioxidant activity correlated with the number of hydroxyl groups as well as lipophilicity of the molecules.

\subsection{Anticarcinogenic/antitumoral activity}

The critical success factor in cancer chemoprevention is the capacity of the agent to selectively inhibit proliferation and/or induce apoptosis in malignant cells, preserving normal cells. Pomegranate, consumed as whole fruit, juice, or any form of derivates, possess anti-proliferative, pro-apoptotic, and/or anti-angiogenic effects superior to those observed with their isolated active compounds, suggesting therapeutic strategies that may depart from preference for pure single agents. There are several publications on the anticarcinogenic effects of pomegranate (Ahmed et al., 2005; Jeune et al., 2005; Malik et al., 2005; Syed et al., 2007; Lansky \& Newman, 2007; Hajimahmoodi et al., 2008; Jurenka, 2008, Sartippour et al. 2008; Adams et al., 2010; Adhami et al., 2010; Faria \& Calhau, 2010,2011; Miguel et al., 2010). Therefore, due to the vast explosion of interest in pomegranate as a functional food and therapeutic source the present work is launched to make a review that highlights anticarcinogenic activity of pomegranate and its products of recently published works.

\subsubsection{Prevention of skin cancer}

There is an urgent need to develop mechanism-based approaches for the prevention/therapy of lethal skin cancer (non-melanoma). Skin is the organ most accessible to sunlight, and directly suffers from the deleterious effects of ultraviolet (UV) 1 radiation, that is known to accelerate aging changes, causing fine and coarse wrinkling, rough skin texture, dryness, telangiectasia and dyspigmentation, resulting in skin cell DNA damage (Afaq, 2011). The increase in incidinces of skin cancer due to constant exposure of skin to environmental carcinogens, such as chemical agents and ultraviolet radiation, provides a strong basis for chemoprevention (Gupta \& Mukhtar, 2002). There is a considerable attention on the use of naturally occurring botanicals for their potential preventive effect against UV-mediated damages referred to as photochemopreventive effects (Afaq et al., 2005). In general, skin carcinogenesis, being a stepwise process of all three distinct stages, is an effective model for cancer chemoprevention (Richmond \& Viner, 2003).

Hora et al. (2003) investigated pomegranate seed oil (PSO) stated that PSO appears to be a natural product with potential as a topical chemopreventive agent against skin cancer, through inhibition of PG biosynthesis and ornithine decarboxylase. PSO treatment did not delay the appearance of tumors, but significantly decreased the rate of tumor development, skin tumor multiplicity, and ornithine decarboxylase activity during 20 weeks of promotion. They stated that PSO, being rich in punicic acid, has inhibitory effect on PG biosynthesis, as well as inhibiting upstream eicosanoid enzyme, phospholipase A2.

Murthy et al. (2004) studied the wound healing activity of phenol-rich methanolic extract of dried pomegranate peel on the skin of Wistar rats. Following the application of the extract, formulated as a water-soluble gel, the animals treated with $5 \%$ gel showed complete healing 
after 10 days, whereas in rats treated with $2.5 \%$ gel, healing was observed on day 12, in contrast to the positive control animals receiving the blank gel, which took 16-18 days for complete healing. The animals treated with $2.5 \%$ gel showed moderate healing $(55.8 \%$ and $40.8 \%$ healing compared with negative and positive controls, respectively), whereas the group treated with $5.0 \%$ gel showed good healing $(59.5 \%$ and $44.5 \%$ healing compared with negative and positive controls, respectively). Histopathological studies supported the wound healing increased on application of the gels.

Afaq et al. (2005) showed that pretreatment of mouse skin with pomegranate fruit extract modulated the activation of mitogen-activated protein kinase (MAPKs) and nuclear factor kappa B (NF-kB), in the 12-O-tetradecanoylphorbol 13-acetate (TPA)-induced or ultra violet-B induced skin carcinogenesis model. Aslam et al. (2006) assessed the cosmeceutical value of pomegranate where aqueous fraction of the peel was shown to stimulate type I procollagen synthesis and inhibit MMP-1 production by human dermal fibroblasts. Syed et al. (2006) reported the remarkable photochemopreventive effects of pomegranate fruit extract (PFE) against UVA using normal human epidermal keratinocytes (NHEK) as a test system. PFE, extracted edible part of fruit with acetone, treatment was shown to inhibit UVA-induced phosphorylation of STAT3, ERK1/2 and AKT1 in human epidermal cells. In addition, the inhibitory effect of PFE on UVA-mediated phosphorylation of mTOR and p70S6K may have a regulatory effect on the rate of protein synthesis and activation of tumor cell proliferation.

In a study pretreatment of EpiDerm with pomegranate juice, oil or by-product resulted in marked inhibition in the number of cyclobutane primidine dimers (CPDs) and 8-hydroxy-2deoxyguanosine $(8-\mathrm{OHdG})$ positive cells, ultimately, showing a protective effect of against UVB-mediated DNA damage. UVB irradiation results in the induction in metalloproteinases (MMPs) which degrade extracellular matrix proteins, and eventually, cause skin wrinkling. It was shown that all three components of pomegranate were able to inhibit UVB-induced expressions of MMPs as well as MMP-2 and MMP-9 activity in the EpiDerm (Zaid et al., 2007). Cell culture and animal studies have also supported that intake of pomegranate is associated with decreased skin cancer risk (Pacheco-Palencia et al., 2008). Afaq et al. (2009) found that pretreatment of human reconstituted skin (EpiDermTM FT-200) with pomegranate-derived products inhibited UVB-induced CPDs and 8-OHdG as well as protein oxidation and proliferating cell nuclear antigen (PCNA) protein expression. In addition they reported an inhibition of UVB-induced metalloproteinases (collagenase, gelatinase, stromelysin, marilysin, elastase and tropoelastin).

George et al. (2011) examined the chemopreventive efficacy of pomegranate fruit extract (PFE) and diallyl sulfide (DAS), alone and in combination, using 2-stage mouse skin tumorigenesis model. PFE alone delayed onset and tumor incidence by 55\%, while in PFE+DAS combination at low doses synergistically decreased tumor incidence more potentially $(84 \%)$. In addition, regression in tumor volume was seen with continuous combinatorial treatment $(p<0.01)$. Mechanistic studies revealed that this inhibition was associated with decreased expression of phosphorylated ERK1/2, JNK1 and activated NF$\kappa \mathrm{B} / \mathrm{p} 65$, IKKa, IкBa phosphorylation and degradation in skin tissue/tumor. Histological and cell death analysis also confirmed that combined PFE and DAS inhibit cellular proliferation and markedly induce apoptosis than the single agents. 


\subsubsection{Prevention of prostate cancer}

Prostate cancer is the second-leading cause of cancer-related deaths in men in the World. In vitro studies stated several pomegranate products inhibit prostate cancer cell growth, induce apoptosis of several prostate cancer cell lines, suppress invasive potential of PC-3 cells, and decrease proliferation of DU-145 prostate cancer cells (Lansky et al., 2005a,b; Pantuck et al., 2006). Albrecht et al. (2004) showed that pomegranate seed oil (PSO) as well as polyphenols present in the pericarp and fermented juice suppress proliferation and invasion of several human prostate cancer cells, LNCaP, PC-3 and DU-145 across the matrigel matrix. Supraadditive, complementary and synergistic effects were proven in all models. Lansky et al (2005b) found equally combined amounts of pomegranate fermented juice, pomegranate pulp juice, cold-pressed pomegranate seed oil extracts resulted in a $99 \%$ suppression of DU145 prostate cancer cell invasion across a matrigel matrix. Ellagic acid, caffeic acid, luteolin and punicic acid, important components of pomegranate significantly inhibited in vitro invasion of human PC-3 prostate cancer cells when employed individually.

Malik et al. (2005) showed that pomegranate fruit extract exhibited significant antiproliferative and pro-apoptotic activity against highly aggressive human PC-3 cells. The cell growth inhibition was dose-dependent, and alterations were in the regulatory molecules responsible in the G1 phase of the cell cycle. Another molecular mechanism through which pomegranate fruit extract is capable of inducing apoptosis in prostate cancer cells may be up-regulation of Bax and down-modulation of Bcl-2. PFE intake was observed to significantly slow the progression of tumor growth in athymic nude mice implanted with androgen-responsive CWR22R-1 cells. Importantly, this tumor growth inhibition followed a significant decrease in the serum levels of PSA.

Pantuck et al. (2006) studied the effects of pomegranate juice consumption on prostatespecific antigen (PSA) progression in men with a rising PSA following primary therapy. A phase II, Simon two-stage clinical trial for eligible men patients with rising PSA after surgery or radiotherapy was conducted. The eligible patients had previous surgery or radiation therapy for prostate cancer, Gleason score $\leq 7$, rising PSA value of $0.2-5.0 \mathrm{ng} / \mathrm{mL}$, no prior hormonal therapy, and no evidence of metastases. Patients were treated with 8 ounces of pomegranate juice daily until disease progression. Mean PSA doubling time significantly increased with treatment from a mean of 15 months at baseline to 54 months posttreatment. In vitro assays comparing pretreatment and posttreatment patient serum on the growth of LNCaP showed a $12 \%$ decrease in cell proliferation and a $17 \%$ increase in apoptosis, a $23 \%$ increase in serum nitric oxide, and significant reductions in oxidative state and sensitivity to oxidation of serum lipids, after versus before pomegranate juice consumption.

Prostate cancer is dependent on circulating testosterone in its early stages and is treatable with surgery, radiation therapy, stereotactic radiosurgery, and proton therapy. Both androgen and androgen receptor (AR) are recognized risk factors in the development of prostate cancer (Heinlein \& Chang, 2004). Reduction of circulating levels of androgens and suppression of AR are crucial for the treatment of prostate cancer as an elevated level of androgen causes enhancement of prostate cancer (Attard et al., 2006). Pomegranate extracts has been shown to inhibit both androgen-dependent and androgen-independent prostate cancer cell growth. Since androgen and AR play central roles throughout prostate cancer development Hong et al. (2008) examined the effects of pomegranate polyphenols, 
ellagitannin-rich extract and whole juice extract on the expression of genes for key androgen-synthesizing enzymes [HSD3B2 (3 $\beta$-hydroxysteroid dehydrogenase type 2), AKR1C3 (aldo-keto reductase family 1 member C3) and SRD5A1 (steroid 5a reductase type 1)] and AR in LNCaP, LNCaP-AR and DU-145 human prostate cancer cells. Pomegranate polyphenols inhibited gene expression and AR most consistently in the LNCaP-AR cell line. Therefore, inhibition by pomegranate polyphenols of gene expression involved in androgensynthesizing enzymes and the AR may be of particular importance in androgenindependent prostate cancer cells and the subset of human prostate cancers where AR is upregulated.

Since the anticarcinogenic activity of ellagic acid, the main polyphenol in the pomegranate, has been shown on several cancer types Malik et al. (2011) evaluated the effect of ellagic acid treatment on the cell viability of human prostate cancer cells. They observed that ellagic acid (10-100 mol/L) treatment $(48 \mathrm{~h})$ of human prostate carcinoma PC3 cells resulted in a dose dependent inhibition of cell growth/cell viability. Ellagic acid caused cell growth inhibition which was accompanied by induction of apoptosis, as assessed by the cleavage of poly (ADP-ribose) polymerase (PARP) and morphological changes. Further, ellagic acid treatment was also found to result in significant activation of caspases, as shown by the dose dependent decrease in the protein expression of procaspase-3, $-6,-8$ and -9 . This ellagic acidmediated induction of apoptosis was significantly (80-90\%) inhibited by the caspase inhibitor N-benzyloxycarbonyl-Val-Ala-Asp (OMe) fluoromethylketone (Z-VAD-FMK).

In a study, Koyama et al. (2010) investigated the relationship between pomegranate-induced apoptosis in human prostate cancer cells and the insuline-like growth factor (IGF)/IGF binding protein (IGFBP) system, as the IGF axis is critical for the regulation of apoptosis in many human cancer cell lines and IGFBPs in serum are responsible for regulation of IGF action, inhibition of cell proliferation and enhancement of apoptosis in many cell types, including prostate (Rajah et al., 1997) and breast (Gucev et al., 1996; Kim et al., 2004) cancers. They concluded that there are novel interactions between the IGF system and pomegranateinduced apoptosis, and pomegranate products modulate the tumor production and responsiveness to IGFs and the IGFBPs. Treatment of LAPC-4 prostate cancer cells with 10 $\mu \mathrm{g} / \mathrm{mL}$ pomegranate extract, standardized to ellagitannin content ( $37 \%$ punicalagins by HPLC), resulted in inhibition of cell proliferation and induction of apoptosis. Co-treatment with pomegranate extract and IGFBP-3 revealed synergistic stimulation of apoptosis and additional inhibition of cell growth. The researchers also investigated the relationship between IGF-1 and pomegranate-induced apoptosis in 22RV-1 prostate cancer cells. Cotreatment with $100 \mathrm{ng} / \mathrm{mL}$ IGF-1 completely blocked apoptosis induction by pomegranate extract. In contrast, IGF-I failed to inhibit pomegranate-induced apoptosis in R- cells, suggesting the importance of IGF-IR. POMx-treatment decreased Igf1 mRNA expression in a dose-dependent manner indicating that its actions also involve tumor-specific suppression of IGF-1.

\subsubsection{Prevention of breast cancer}

Along with enthusiastic efforts in early diagnosis, aggressive surgical treatment and application of additional non-operative modalities, the prognosis of breast cancer is stil chaotic. Pomegranate has been the target of several work in laboratories and cancer centres and known to have inhibition properties against diverse types of cancers. Recent review 
articles reported the laboratory and clinical evidence of cancer chemoprevention or treatment of pomegranate fruit, pomegranate juice, pomegranate seed and seed oil on prostate, breast, skin, colon, lung, oral and leukaemia cancers, through antioxidant, antiproliferation, antiangiogenesis and antiinflammatory mechanisms of action (Adhami et al., 2009,2010; Amin et al., 2009; Faria \& Calhau, 2011; Johanningsmeier \& Harris, 2011). They all reported that extracts of pomegranate or the juice are generally more active than individual or purified compounds.

The antiangiogenic potential of pomegranate was evaluated by Toi et al. (2003) where VEGF, interleukin-4 and migration inhibitory factor (MIF) were measured in the conditioned media of estrogen sensitive MCF-7, estrogen resistant MDA-MB-231 human breast cancer cells and MCF-10A immortalized human breast epithelial cells, grown in the presence or absence of pomegranate seed oil or fermented juice polyphenols. Polyphenols from fermented pomegranate juice, pericarp and oil were shown to inhibit endogenous active estrogen biosynthesis with subsequent inhibition of aromatase activity. VEGF was strongly downregulated in MCF-10A and MCF-7 cells, and MIF upregulated in MDAMB231 cells, representing a marked potential for downregulation of angiogenesis by pomegranate fractions. Mehta \& Lansky (2004) examined the effects of pomegranate fermented juice, cold pressed pomegranate seed oil extract and an HPLC-isolated peak (from the fruit extract-peak B), using the mouse mammary organ culture, an animal model of breast cancer having $>75 \%$ accuracy to predict in vivo carcinogenesis. They showed that the purified chromatographic peak of pomegranate fermented juice polyphenols and pomegranate seed oil possesses greater chemopreventive potential than that previously reported by Kim et al. (2002). While fermented juice polyphenols effected a $42 \%$ reduction in the number of DMBA-induced cancerous lesions compared with control, purified compound, peak B, and pomegranate seed oil each effected an $87 \%$ reduction. Peak B is believed to be a phenolic compound with potent chemopreventative properties. Combination treatment of MCF-7 breast cancer cells with both pomegranate extracts and genistein was found to be more effective on inhibition and cytotoxicity than with single treatments (Jeune et al., 2005).

In an ethnobotanical study of medicinal plants in Chandauli District, Singh \& Singh (2009) were able to document 40 medicinal plants belonging to 27 families by semi-structured interviews, field observations, preference and direct matrix ranking with traditional medicine practitioners. Pomegranate was found to be an ingredient of a powder for external treatment of breast cancer along with whole plant of Vernonia cinerea Less. (AS38) and leaves of Crataeva nurvala.

Epidemiological studies have demonstrated that elevated serum levels of the estrogens, mainly estrone and estradiol, and lower levels of sex hormone binding globulin, after menopause substantially increased the risk of breast cancer. After menopause, most circulating estrogen is derived from the conversion of adrenal androgens to estrone, and some of the estrone is further converted to estradiol, the most active estrogen in breast tissue. Sturgeon \& Ronnenberg (2010) described the in vitro cell culture studies, animal studies and available data about the property of pomegranate to prevent breast cancer as well as the possible mechanisms involved. They reported that cyclooxigenase inhibition by the constituents of the pomegranate fruit, seed oils or pure compounds induce the decrease of PGE2 that known to downregulate aromatase expression, that converts adrenal 
androgens to estrone. Ellagic acid seems to exhibit apoptosis, inhibits activation of inflammatory pathways, and inhibits angiogenesis. However, these assays being performed in animal models need to be confirmed in humans.

Grossmann et al. (2010) found that punicic acid inhibited the proliferation of estrogen insensitive breast cancer cell line (MDA-MB-231) and an estrogen sensitive cell line developed from the MDA-MB-231 cells (MDA-ER 7), as well as induced apoptosis in both type of cells $86 \%$ and $91 \%$ respectively. They stated that punicic acid also disrupted mitochondrial membrane potential of both cell lines. Such antiproliferative effect of punicic acid on human breast cancer cells was due to lipid peroxidation of cells and activation of protein kinase $\mathrm{C}(\mathrm{PKC})$.

Tran et al. (2010) evaluated pomegranate seed linolenic acid isomers as selective estrogen receptor modulators (SERMs) in vitro. Punicic acid and $\alpha$-eleostearic acid present in seed oil of pomegranate inhibited the $\mathrm{IC}_{50}$ estrogen receptors $\mathrm{ER} \alpha$ and $\mathrm{ER} \beta$ depending on the dose. At lower doses of punicic acid acted as agonist for both receptors and antagonist at higher concentrations. Both acids were effective in producing effective inhibition of cancer cell proliferation: MCF-7 (ER-positive human breast cancer cells) and MDA-MB-231 (ERnegative human breast cancer cells and are SERMs.

\subsubsection{Prevention of colon cancer}

Current treatment options in colorectal cancer such as surgical intervention and adjuvant chemotherapy have several limitations in counteracting the disease. Furthermore, at advanced stages the patients might be unresponsive to any form of treatment. In this regard, an optimal model for primary and secondary prevention in colon cancer, given the availability of effective screening procedures and a well-defined multi-step carcinogenic pathway, can be thought as the development of new cancer chemopreventive agents that could be employed to inhibit tumor development without causing systemic toxicity such as increasing the consumption of food containing anticarcinogenic compounds. Phytochemicals from pomegranate have been shown to inhibit colon cancer cell proliferation and apoptosis through the modulation of cellular transcription factors and signaling proteins (Mertens-Talcott \& Percival, 2005; Seeram et al., 2006; Khan, 2009; Kasimsetty et al., 2010).

Kohno et al. (2004a,b) reported that dietary administration of pomegranate seed oil rich in conjugated linolenic acid markedly inhibited the development of azoxymethane-induced colonic adenocarcinomas in male F344 rats without causing any adverse effects. This was associated with an increased content of conjugated linoleic acid in the colon and liver and/or increased expression of peroxisome proliferator-activated receptor (PPAR)-protein in the non-tumor colon mucosa.

There is considerable evidence that the anticarcinogenic effect of pomegranate ellagitannins is mainly due to ellagic acid, which induces apoptosis in human colon cancer cell line via the intrinsic pathway with release of cytochrome $c$ into the cytosol, activation of initiator caspase 9 and effector caspase 3 and down-regulation of B-cell lymphoma-extra large (Bcl$\mathrm{XL}$ ). In addition, pomegranate treated Caco-2 cells showed arrest in the $\mathrm{S}$ phase of the cell cycle, down-regulation of cyclins A and B1 and upregulation of cyclin E (Larossa et al., 2006). 
Adams et al. (2006) examined the effects of pomegranate juice on inflammatory cell signaling proteins in the HT-29 human colon cancer cell line. In HT-29 colon cancer cells, at a concentration of $50 \mathrm{mg} / \mathrm{L}$ pomegranate juice significantly suppressed TNFalpha-induced COX-2 protein expression by $79 \%$, total pomegranate tannin extract (TPT, 55\%), and punicalagin $48 \%$ Cyclooxygenase-2 (COX-2) expression is increased via activation of nuclear factor kappa-B (NFKB) by tumor necrosis factor-alpha (TNF-Ot), an inflammatory cell signaling process that may be a cause of cancer initiation and progression. Additionally, pomegranate juice reduced phosphorylation of the p65 subunit and binding to the NFkappaB response element 6.4-fold. TPT suppressed NFK binding 10-fold, whereas punicalagin 3.6-fold. It was shown that inflammatory enzymes in colon cancer cells were inhibited by the pomegranate juice components. Ellagic acid, punicalagin and TPT failed to induce apoptosis in HT-29 and HCT-116 cells when treated at doses equivalent to found in pomegranate juice. They were only effective when treated at equivalent doses of $100 \mu \mathrm{g} / \mathrm{mL}$ (Seeram et al., 2005).

In a seperate study, Boateng et al. (2007) examined the effect of pomegranate juice given access to $20 \%$, before and after treatment with colon-specific chemical carcinogen, azoxymethanein to F-344 rats for 17 weeks. Pomegranate fruit juice reduced the number of aberrant cryptic foci (ACF) of the colon by $91 \%$ in male rats. Histopathology of rat colon after 17th week of treatment revealed a remarkable decrease in the number of large crypts in pomegranate juice-fed rats, and the number of crypts/ACF was also low. When compared to water melon and cranberry juices, pomegranate juice was found to be superior as an inhibitor of ACF in rat colon. Increase in weight gain and feed intake was observed in pomegranate fruit juice-fed rats, suggesting a possible protective effect against cancer cachexia.

Kasimsetty et al. (2010) investigated the colon cancer chemopreventive properties of pomegranate ellagitannins and their intestinal bacterial metabolites, urolithins, in HT-29 human colon cancer cells, and stated that the ellagitannins and urolithins released in the colon upon consumption of pomegranate juice in considerable amounts could potentially reduce the risk of colon cancer development, by inhibiting cell proliferation and inducing apoptosis. Ellagitannins and urolithins inhibited endocrine disrupter 2,3,7,8tetrachlorodibenzo- $p$-dioxin (TCDD)-induced CYP1-mediated ethoxyresorufin-O-deethlyase (EROD) activity in vitro with $\mathrm{IC}_{50}$ values ranging from $56.7 \mu \mathrm{M}$ for urolithin A to $74.8 \mu \mathrm{M}$ for urolithin C. These compounds exhibited dose- and time-dependent decreases in cell proliferation and clonogenic efficiency of HT-29 cells.

In colon cancer, a large percentage of the tumour arises from activating mutations in the Wnt protein pathway. Sharma et al. (2010) studied the effects of urolitinins, ellagic acid and ellagitannin-rich fruit extracts on Wnt signalling in a human 293T cell line using a luciferase reporter of canonical Wnt pathway-mediated transcriptional activation. In the canonical Wnt pathway, the signal produced by the binding of Wnt ligands to cell surface receptors is transmitted through a cytoplasmic protein called disheveled (Dvl) to inhibit the activity of a complex of cellular proteins that phosphorylate $\beta$-catenin, and target it for destruction. Therefore, Dvl-mediated inhibition of the $\beta$-catenin destruction complex results in increased levels of cellular $\beta$-catenin and translocation of $\beta$-catenin into the nucleus, where $\beta$-catenin activates transcription factors of the LEF/TCF families and initiates transcription of target genes effective on tissue proliferation, differentiation and tumorigenesis. The researchers 
concluded that urolithins produced in the colon from ellagitannins present in pomegranate are inhibitors of the canonical Wnt signalling pathway at physiologically relevant concentrations.

\subsubsection{Prevention of other cancer types}

Eventhough there are advances in detection and therapy of cancer, the severe morbidity rate from cancer have not improved. Various parts of the pomegranate plant have been stated to exert selective antiproliferative effects on a lung, leukemia, stomach, bladder, oesaphagus and oral cancers (Lansky \& Newman, 2007; Syed et al., 2007; Heber, 2008; Jurenka, 2008; Rahman et al., 2010; Khan \& Mukhtar, 2010; Faria \& Calhau 2011), through antioxidant, antiproliferation (growth inhibition, cell cycle disruption and apoptosis), antiangiogenesis and antiinflammatory mechanisms of action.

In vitro and in vivo studies revealed that pomegranate fruit extract (PFE) have chemopreventive/therapeutic potential of against lung cancer models (Khan et al., 2007a,b,2008). Normal human bronchial epithelial cells (NHBE) and human lung carcinoma A549 cells, in mice, were treated with pomegranate fruit extract $(50-150 \mu \mathrm{g} / \mathrm{ml})$ for $72 \mathrm{~h}$. There was a significant decrease in the viability of A549 cells, however, only minimal effects were observed on NHBE cells. Pomegranate fruit extract treatment of A549 cells resulted in dose-dependent arrest of cells in G0/G1 phase of the cell cycle, which was associated with induction of WAF1/p21 and KIP1/p27 and accompanied by decrease in the expression of downstream cell cycle regulatory proteins (Khan et al., 2007a).

The effect of oral consumption of a human achievable dose of pomegranate fruit extract on tumor growth, progression and signaling pathways involved, was studied further in two other mouse lung tumor protocols. Benzo(a)pyrene $[\mathrm{B}(\mathrm{a}) \mathrm{P}]$ and N-nitroso-trischloroethylurea (NTCU) were used to induce lung tumors, and PFE was given in drinking water to A/J mice. Lung tumor yield was examined on the 84 th day and 140 days after $\mathrm{B}(\mathrm{a}) \mathrm{P}$ dosing and 240 days after NTCU treatment. Mice treated with PFE and exposed to B(a)P and NTCU had statistically significant lower lung tumor multiplicities than mice treated with carcinogens only. Tumor reduction was $53.9 \%$ and $61.6 \%$ in the $\mathrm{B}(\mathrm{a}) \mathrm{P}+\mathrm{PFE}$ group at 84 and 140 days, respectively, compared with the $\mathrm{B}(\mathrm{a}) \mathrm{P}$ group. The NTCU+PFE group had $65.9 \%$ tumor reduction compared with the NTCU group at 240 days. PFE treatment also resulted in inhibition of NF-kB, MAPK, and PI3K/Akt signaling. Treatment with B(a)P and NTCU caused increased phosphorylation of mTOR at Ser ${ }^{2448}$, whereas PFE administration resulted in inhibition of phosphorylation of mTOR. This observation was significant since the mTOR integrates mitogenic signals and intracellular nutrient levels to activate 4EBP1 and p70S6K that control protein translation and cell cycle progression (Khan et al., 2007b).

Suzuki et al. (2001) investigated cytotoxicity of pomegranate seed oil and other plant seed oils containing conjugated linoleic acids in mouse tumors and human monocytic leukemia cells. They stated the cytotoxic effect of pomegranate seed oil (containing 9c,11t,13c-18:3), as well as tung seed oil (containing 9c,11t,13t-18:3) and catalpa seed oil (containing 9t,11t,13c18:3), was much stronger than that of pot marigold seed oil (containing 8t,10t,12c-18:3), suggesting that the position of the double bond could be an important determinant for the cytotoxicity of conjugated inoleic acids.

Kawaii \& Lansky (2004) examined the effect of flavonoid-rich pomegranate juice, pomegranate fermented juice and pomegranate pericarp extracts on HL-60 human leukemia 
cell differentiation and proliferation. In vitro assays confirmed that both the pomegranate fermented juice and pericarp extracts strongly promoted cellular differentiation and inhibited proliferation in HL-60 cell cultures; the effect of pomegranate juice on cellular differentiation was less significant. In view of the observations the authors stated the hypothesis of another mechanism by which pomegranate constituents impart an anticarcinogenic effect.

Mertens-Talcott \& Percival (2005) investigated the interactions of ellagic acid and quercetin with resveratrol, with the hypothesis that the selected polyphenols would interact synergistically in the induction of apoptosis and reduction of cell growth in human leukemia cells (MOLT-4). They found significant interaction for the combination of ellagic acid with resveratrol, and alterations in cell cycle kinetics induced by single compounds and combinations were also observed. The authors concluded that the anticarcinogenic potential of foods containing polyphenols may not be based on the effects of individual compounds, but may involve a synergistic enhancement of the anticancer effects.

\subsection{Other health effects}

\subsubsection{Antiinflammatory activity}

Epidemiological evidence points that many cancers arise from sites of infection, chronic irritation and inflammation (Rakoff-Nahoum, 2006; Heber, 2008). The inflammatory response result in persistent oxidative stress orchestrates tumour microenvironment to microbial infection and mediates tissue repair and regeneration, which may occur due to infectious or non-infectious tissue damage.

Pomegranate and the selected chemical constituents isolated from juice, peel, and seed have been found to have a large range of effects: (i) inhibition of Cyclooxygenase-2 (COX2) expression and ultimately eicosanoid biosynthesis (Schubert et al., 1999; Shukla et al., 2008); (ii) synergistic suppression of inflammatory cytokine expression (Adams et al., 2006); (iii) inhibition of matrix MMPs (Okamoto et al., 2004; Ahmad et al., 2005; Aslam et al., 2006).

In view of the antioxidant, anticarcinogenic and antiinflammatory properties of pomegranate phenolics and/or its derived metabolites, one could hypothesize that pomegranate and/or its derived metabolites have a beneficial effect on inflammation. Larrosa et al. (2010) evaluated the effects of pomegranate intake and its main microbiotaderived metabolite urolithin-A (UROA) on colon inflammation in a dextran sodium sulfate (DSS)-induced colon inflammation rat model and to assess whether UROA is the main antiinflammatory compound. In addition, they examined the effect of the inflammation on the phenolic metabolism. DSS (5\%) was administered for the five last days to Male Fisher rats, fed with $250 \mathrm{mg} / \mathrm{kg}$ day pomegranate extract or $15 \mathrm{mg} / \mathrm{kg}$ day UROA for 25 days. In both groups inflammation markers (iNOS, COX-2, PTGES and PGE2 in colonic mucosa) were decreased, the gut microbiota was modulated and the G1 to S cell cycle pathway was upregulated. UROA group showed various down-regulated pathways, including that of the inflammatory response. Pomegranate extract, but not UROA, decreased oxidative stress in plasma and colon mucosa. Only UROA preserved colonic architecture. The normal formation of urolithins in pomegranate extract-fed rats was prevented during inflammation suggesting UROA could be the most active anti-inflammatory compound derived from 
pomegranate ingestion in healthy subjects, whereas in colon inflammation, the effects could be due to the nonmetabolized ellagitannin-related fraction.

Structure-activity relationships of natural products have been found to influence the various pharmacological functions. In vitro and in vivo antiinflammatory effects of Punica granatum Linne, a high phenolic content fruit, widely used as an antipyretic analgesic in Chinese culture, were investigated by Lee et al. (2010). Pomegranate has shown potential nitric oxide (NO) inhibition in liposaccaharide (LPS)-induced RAW 264.7 macrophage cells, with significant decrease in carrageenan-induced mice paw edema. Hydrolysable tannins, punicalagin, punicalin, strictinin A, and granatin B, inhibited NO production and inductible nitric oxide synthase (iNOS) expression in RAW 264.7 cells. Granatin B showed the strongest iNOS and COX-2 inhibitory effects, and exhibited these effects in the inhibition of paw swelling and the prostaglandin (PG) E2 level in carrageenan-induced mice.

Inflammatory disorders are due to excessive production of pro-inflammatory mediators such as TNFa, GM-CSF, IL-1, IL-6, IL-8, leukotriene B4 and PAF, the activity of inflammatory cells such as neutrophils, monocytes and macrophages, and excessive production of reactive oxygen species (ROS) (Nathan, 2006). Bachoual et al. (2011) investigated the effect of pomegranate peel aqueous extract (PPAE) on human neutrophil reactive oxygen species (ROS) production in vitro and on LPS-induced lung inflammation in vivo in mice. PPAE, in a concentration-dependent manner, inhibited luminol-amplified chemoluminescence of resting neutrophils and N-formyl-methionylleucyl- phenylalanine (fMLF)- or phorbol myristate acetate (PMA)-stimulated neutrophils. On the contrary, had no significant effect on superoxide anion generation, suggesting that it does not directly inhibit NADPH oxidase activity or activation pathways, or scavenge superoxide anions. In vivo studies showed that PPAE also attenuated LPS-induced lung inflammation in mice. Consequently PPAE found to inhibit neutrophil myeloperoxidase activity and attenuates LPS-induced lung inflammation in mice.

\subsubsection{Cardiovascular health}

Cardiovascular diseases (CVDs) are a leading cause of death and disability worldwide. Hypertension and atherosclerosis, a chronic inflammatory disease characterized by plaque formation in the large arteries, are major risk factors for CVDs, such as stroke, myocardial infarction and heart failure. In addition to genetic factors, age, body weight, blood pressure, dyslipidemia, physical inactivity and behavioural risk factors such as tobacco or alcohol use, diets that include high fat, salty food are thought to play an important role in the development of cardiovascular disease. Epidemiological data have clearly shown that independent risk factors for CVD are serum total cholesterol and low-density lipoprotein cholesterol (LDL-C) (Kannel et. al., 1986; Mirmiran et al., 2009). A large number of clinical trials have demonstrated in order to prevent these cardiovascular diseases from occurring, control of a patient's blood pressure is necessary, either by lifestyle modifications, medication(s) such as use of cholesterol-lowering statins, antihypertensive drugs and antiplatelet agents or both.

While modification of dietary patterns and increased physical activity constitute the primary preventive intervention in lowering coronary heart disease (CHD) and stroke, the role of plant-based bioactive compounds or phytochemicals has attracted much attention since 
there is a negative relationship between their consumption and CVDs (Hu, 2003; Dauchet et al., 2005; Nothlings et al., 2008). Pomegranate, being rich in flavonoids and ellagitannins, are potent antioxidants and antiinflammatory agents, thereby counteracting oxidative damage and inflammation which underlie the pathogenesis of CVD (Kaplan et al., 2001). Oxidative stress, the major contributor to CVD, is the build-up of highly reactive free radical species or the decrease of defence mechanisms to protect against biological damage by free radicals due to the imbalance between free radical formation and antioxidant status. Oxidative stress induces inflammation by acting on the pathways that generate inflammatory mediators like adhesion molecules and pro-inflammatory cytokines. The effect of reactive oxygen species (ROS) and reactive nitrogen species (RNS) on human health has been studied for decades, with results indicating increasing the risk of cancer, arthritis, degenerative eye and neurological disorders, as well as general aging (Aruoma, 1998). However, the attention has turned to the effect of these free radicals on CVD and related disorders; such as atherosclerosis, hypertension, hypercholesterolemia, type 2 diabetes, and heart failure (Hamilton et al., 2004).

Sumner et al. (2005) investigated the effect of daily consumption of pomegranate juice for 3 months on myocardial perfusion in patients who had coronary heart disease and myocardial ischemia in a randomized, placebo-controlled, double-blind study. The patients were given either $240 \mathrm{~mL}$ pomegranate juice (polyphenol content not specified) or a sports beverage of similar color, flavor, and caloric content daily for three months. Although both control and treatment patients demonstrated similar levels of stress-induced ischemia at baseline, at three months stress-induced ischemia decreased in the treatment group (from $4.5 \pm 3.1$ to $3.7 \pm 3.7$ ). In addition, angina episodes decreased $50 \%$ percent in the treatment group but increased $38 \%$ in the placebo group. The researchers concluded that pomegranate juice consumption resulted in a reduction in myocardial ischemia and improvement in myocardial perfusion.

Rosenblat et al. (2006) studied the antiatherosclerotic effects of a pomegranate by-product (PBP, which includes the whole pomegranate fruit left after juice preparation). Fourmonth-old $\mathrm{E}^{\circ}$ mice with significant atherosclerosis were given PBP (17 or $51.5 \mu \mathrm{g}$ of gallic acid equiv/ $/ \mathrm{kg} /$ day) with an eight-fold higher polyphenol concentration than pomegranate juice for three months. Consumption of PBP by the mice resulted in a significant reduction in atherosclerotic lesion size by up to $57 \%$ and in MPM oxidative status as evidenced by a $27 \%$ decrease in total macrophage peroxide levels, a $42 \%$ decrease in cellular lipid peroxide levels, and a 19\% decrease in peritoneal macrophage uptake of oxidized LDL (Ox-LDL).

Through in vitro and in vivo studies de Nigris et al. (2006) stated that the proatherogenic effects induced by perturbed shear stress can be also reversed by chronic administration of pomegranate fruit extract (PFE). The researcher investigated the effects of intervention with the PFE rich in polyphones (punicalagin, which is a potent antioxidant) on ELK-1, p-CREB, and endothelial nitric oxide synthase (eNOS) expression induced by high shear stress. Both the PFE and the regular pomegranate juice concentrate reduced the activation of ELK-1 and p-CREB and increased eNOS expression in cultured human endothelial cells and in atherosclerosis-prone areas of hypercholesterolemic mice. PFE and pomegranate juice increased cyclic GMP levels while there was no significant effect of both compounds on the conversion of L-arginine to L-citrulline. Administration of these compounds to 
hypercholesterolemic mice significantly reduced the progression of atherosclerosis and isoprostane levels and increased nitrates.

In a randomized, double-blind, parallel trial Davidson et al. (2009) assessed the influence of pomegranate juice consumption on anterior and posterior carotid intima-media thickness (CIMT) progression rates in subjects at moderate risk for coronary heart disease. Participants consumed $240 \mathrm{ml} /$ day of pomegranate juice or a control beverage for up to 18 months. No significant difference in overall CIMT progression rate was observed between pomegranate juice and control treatments. In exploratory analyses, in subjects in the most adverse tertiles for baseline serum lipid peroxides, triglycerides (TGs), highdensity lipoprotein (HDL) cholesterol, TGs/HDL cholesterol, total cholesterol/HDL cholesterol, and apolipoprotein-B100, those in the pomegranate juice group had significantly less anterior wall and/or composite CIMT progression versus control subjects. They concluded that in subjects at moderate coronary heart disease risk, pomegranate juice consumption had no significant effect on overall CIMT progression rate but may have slowed CIMT progression in subjects with increased oxidative stress and disturbances in the TG-rich lipoprotein/HDL axis.

Endothelial apoptosis is a driving force in atherosclerosis development. Oxidized lowdensity lipoprotein (oxLDL) promotes inflammatory and thrombotic processes and is highly atherogenic, as it stimulates macrophage cholesterol accumulation and foam cell formation. In recent years ellagic acid has been the subject of intense research within the fields of cancer and inflammation, however, its protective effect against oxidized LDL-induced injury in vascular endothelial cells have not been clarified. Ou et al. (2010) investigated the antiapoptotic effect of ellagic acid in human umbilical vein endothelial cells (HUVECs) exposed to OxLDL and explored the possible mechanisms. Pretreatment with ellagic acid $(5-20 \mu \mathrm{M})$ significantly attenuated OxLDL-induced cytotoxicity, apoptotic features, and generation of ROS. In addition, the antiapoptotic effect of ellagic acid was partially inhibited by wortmannin (a PI3K inhibitor) and cavtratin (a specific endothelial NO synthase inhibitor). The alterations induced by OxLDL, however, were attenuated by pretreatment with ellagic acid. The inhibition of OxLDL-induced endothelial apoptosis by ellagic acid is due to its anti-oxidant activity and its ability to modulate the PI3K/Akt/eNOS signaling pathway upto a point.

\subsubsection{Antidiabetic properties (glucose and lipid metabolism activity)}

According to several review articles (Jurenka, 2008; Li et al., 2008; Yun, 2010) pomegranate flowers, containing abundant ellagitannins, was already prescribed in Unani and Ayurvedic systems of medicine as a remedy for diabetes. The protective effect of pomegranate flowers' extracts (PFLE) was investigated by some authors on blood glucose level, serum lipid profile, total cholesterol, LDL, pancreatic lipid peroxidation and activities of both enzymatic and non-enzymatic antioxidant status in diabetic rats (Huang et al., 2005a,b; Lei et al., 2007; Lan et al., 2009; Bagri et al., 2009). The authors reported that the increase in blood glucose level, total cholesterol, triglycerides, LDL-cholesterol, very low density lipoproteins, lipid peroxidation level with decrease in high density lipoprotein (HDL)-cholesterol, glutathione content and antioxidant enzymes namely, glutathione peroxidase, glutathione reductase, glutathione-S-transferase, superoxide dismutase and catalase can be reversed by administration of aqueous PFLE. PFLE was shown to activate PPAR-a, a cardiac 
transcription factor involved in myocardial energy production via fatty acid uptake and oxidation. PPAR-a activation decreased cardiac uptake and circulation of Iipids. Decreases were observed in cardiac tissue triglycéride content at the end of the study and in plasma total cholesterol and NEFA after four weeks of treatment.These findinds suggest that pomegranate could be used as dietary supplement in the treatment and prevention of chronic diseases characterised by atherogenic lipoprotein profile, aggravated antioxidant status and impaired glucose metabolism.

Rosenblat et al. (2006) investigated the effect of $50 \mathrm{~mL} /$ day pomegranate juice for three months on oxidative stress, blood sugar, and lipid profiles in 10 type 2 diabetic patients, with a history of diabetes for 4-10 years, and 10 healthy controls. In diabetic patients, triglyceride levels were 2.8 times greater, (HDL) cholesterol was $28 \%$ lower, and hemoglobin $\mathrm{AlC}(\mathrm{HbAlC})$ values were $59 \%$ higher than in control patients. They stated that consuming pomegranate juice for three months did not significantly affect triglyceride, HDL cholesterol, HbAlC, glucose, or insulin values, but did lower serum C-peptide values by $23 \%$, suggesting improved insulin sensitivity. Researchers concluded that despite the sugars naturally present in pomegranate juice, consumption did not adversely affect diabetic parameters but had a significant effect on atherogenesis via reduced oxidative stress.

Esmailzadeh et al. (2006) investigated the cholesterol-lowering effects of $40 \mathrm{~g}$ concentrated pomegranate juice on 22 type 2 diabetic patients ( 8 men and 14 women) for eight weeks. Statistically significant decreases were observed in total cholesterol, LDL cholesterol, total/HDL cholesterol ratio, and LDL/HDL ratio, which due in part to decreased absorption and increased fecal excretion of cholesterol, as well as possible affects on HMG-CoA reductase and sterol O-acyltransferase, two enzymes key to cholesterol metabolism.

Oleanolic acid, ursolic acid and gallic acid, active components contained in pomegranate flower (Li et al., 2008), have long been recognized to have antihyperlipidemic properties (Liu, 1995; Jang et al., 2008). Xu et al. (2009) speculated that PFLE might improve diabetes and obesity-induced fatty liver, and investigated the effects and underlying mechanisms of action of PFLE on hepatic lipid accumulation in ZDF rats with severe fatty liver and in human liver-derived HepG2 cell line. PFLE-treated ZDF rats showed reduced ratio of liver weight to tibia length, hepatic triglyceride contents and lipid droplets. These effects were accompanied by enhanced hepatic gene expression of peroxisome proliferator-activated receptor (PPAR)-alpha, carnitine palmitoyltransferase- 1 and acyl-CoA oxidase (ACO), and reduced stearoyl-CoA desaturase-1. Incontrast, PFLE showed minimal effects on expression of genes responsible for synthesis, hydrolysis or uptake of fatty acid and triglycerides. PGF treatment also increased PPAR-alpha and ACO mRNA levels in HepG2 cells. The authors concluded that PFLE, an Unani medicine, ameliorates diabetes and obesity-associated fatty liver, at least in part, by activating hepatic expression of genes responsible for fatty acid oxidation.

There is growing evidence that paraoxnase (PON1) plays an important role in lipid metabolism, particularly in protecting LDL and HDL from oxidation in vitro, and thus lowering the risk of developing atherosclerosis, and the onset of cardiovascular disease (Mackness et al., 2000,2002). PON1 knockout mice exhibit about a two-fold increase in atherosclerosis (Rozenberg et al., 2003), whereas PON1 expression and activity can be modulated by dietary polyphenols i.e. LDL receptor deficient mice supplemented with quercitine (a polyphenol contained in pomegranate) and moderate ethanol inhibited the 
progression of atherosclerosis by upregulating the hepatic expression with concomitant increased serum PON1 activity (Gouédard et al., 2004; Leckey et al., 2010). Similarly, pomegranate polyphenols seem to have a specific transcriptional role in hepatocyte PON1 expression upregulation (Khateeb et al., 2010). Although it is known that diabetes is associated with increased oxidative stress and the development of atherosclerosis (Mooradian, 2009), no expression studies have been examined in a diabetic model that is fed with high fat. Therefore, Betanzos-Cabrera et al. (2011) investigated whether pomengranate juice induces PON1 gene expression and activity, especially in conditions known for affecting PON1 enzymatic function. The feeding of streptozotocin-induced diabetic mice with a high-fat diet supplemented daily with pomegranate juice significantly induced PON1 gene expression and activity. Interestingly, animals supplemented with pomegranate juice showed the lowest bodyweight. In addition, the pomegranate juice significantly reduced blood glucose but not triacylglycerols and cholesterol levels, demonstrating that pomegranate juice has a hypoglycemic effect.

\subsubsection{Antimicrobial properties}

Due to the increasing interest in natural antimicrobials and antioxidants derived from plant sources the investigation of pomegranate has also been an interesting scientific field for researchers, since the capacity of preventing infections of pomegranate extracts was well documented. Food-borne illnesses are still an important concern for both consumers, the food industry and food safety authorities, thus, the ongoing search for natural antimicrobials for prevention of food-borne illnesses is a vast exploring area for scientists. Antimicrobial activities of pomegranate have been studied by some researchers and the extent of inhibitory effect is always attributed to the pomegranate antioxidant activity that depends mainly on the phenolic and anthocyanin content of the fruit (Holetz et al., 2002; Braga et al., 2005; Mathabe et al., 2006; McCarrell et al., 2008; Al-Zoreky, 2009; Duman et al., 2009; Gould et al., 2009; Parashar et al., 2009; Panichayupakaranant et al., 2010, Orak et al., 2011). In a previous study, Opara et al. (2009) reported that the best activity against Staphyloccocus aureus and Pseudomonas aeruginosa were found in fruit peel compound punicalagin, particularly from Oman, which was coincident with the highest levels of vitamin C detected in these samples. Similar findings were reported by Salgado et al. (2009) and Dahham et al. (2010) in which antibacterial and antifungal activities of pomegranate peel extract (rind), seed extract, juice and whole fruit on the selected bacteria and fungi were investigated. The antimicrobial effectiveness of the extracts depends on the species of bacteria evaluated, the more sensitive being the Gram-positive species S. aureus and Bacillus sp. along with Aspergillus niger. Voravuthikunchai et al. (2006) tested pomegranate and seven other Thai medicinal plant extracts for in vitro activity against enterohemorrhagic Escherichia coli (E. coli O157:H7). An ethanolic pomegranate peel extract was shown to be both bacteriostatic and bacteriocidal, indicating it may be an effective adjunct treatment for $E$. coli O157:H7 infection.

The only human trials examining the antibacterial properties of pomegranate extracts have focused on oral bacteria (Sastravaha et al., 2003; Menezes et al., 2006). However, several in vitro assays demonstrate its bacteriocidal activity against several highly pathogenic and sometimes antibiotic-resistant organisms. Machado et al. (2002) evaluated the synergistic effect of a pomegranate methanolic extract with five antibiotics on 30 clinical isolates of methicilin-resistant $S$. aureus (MRSA) and methicillin-sensitive S. aureus. Antibiotics tested were. Although synergistic activity between the pomegranate extract and tested antibiotics 
(chloramphenicol, gentamicin, ampicillin, tetracycline, and oxacillin) was noted in the $S$. aureus isolates, synergy with ampicillin was the most pronounced. A combination of the two increased the lag time to bacterial growth by three hours and was also bacteriocidal as evidenced by a $72.5 \%$ reduction in methicillin-sensitive organisms and a $99.9 \%$ reduction in MRSA. Bialonska et al. (2009b) stated that commercial extract of pomegranate by-product provided by POM Wonderful (Los Angeles, CA) and punicalagins inhibited the growth of pathogenic clostridia and S. aureus. Nevertheless the probiotic lactobacilli and bifidobacteria were not affected by ellagitannins. These findings lead to the conclusion that the growth inhibition toward pathogenic bacteria could be attributed to the accumulation of ellagitannins in the large intestines, where they interact with complex gut microflora, and lower media $\mathrm{pH}$ due to the presence of punicalagins.

$\mathrm{Su}$ et al. (2010) stated that the combination of pomegranate juice and pomegranate polyphenols was also effective against food-borne viral infectivity and appear to be promising natural remedies for preventing or reducing human norovirus infections. In addition, pomegranate purified polyphenol extract inhibited influenza virus having also a synergistic effect with oseltamivir, since influenza continues to be a major cause of mortality and morbidity eventhough the applications of the vaccines and antiviral therapies (Haidari et al., 2009).

Johann et al. (2010) studying the activity of extracts of some plants used in Brazilian traditional medicine against the pathogenic fungus that causes this Paracoccidioidomycosis, Paracoccidioides brasiliensis, reported that the hexane extract of pomegranate stem exhibited better antifungal activity against the three clinical isolated than other parts of the plant or other fractions of the same plant.

Candida species, a normal component of the human biota in the gastrointestinal tract and oral and vaginal mucosa, can cause superficial infections such as thrush and vaginitis. Endo et al. (2010) reported that punicalagin isolated from pomegranate peels possessed strong activity against Candida albicans and $C$. parapsilosis as well as the combination of punicalagin and fluconazole showed a synergistic interaction. Tayel \& El-Tras (2009) demonstrated that methanol, ethanol and water extracts of pomegranate peels were effective against $C$. albicans growth. In addition, they also proved that pomegranate peel extract aerosol was an efficient method for complete sanitizing of semi-closed places against C. albicans growth, and thereby could contribute for preventing C. albicans contamination and growth in suspected places. Ethnobotanical studies performed in Brazil had demonstrated the utilization of pomegranate in oral health since denture stomatitis is commonly associated with $C$. albicans and some other Candida species (Santos et al., 2009).

Dell'Agli et al. (2009) studied the in vitro antiplasmodial and antimalarial activity of methanolic extracts of a tannin-enriched fraction and of metabolites to estimate their curative efficacy and mechanisms of action. They conclude that methanolic extracts of pomegranate inhibited Plasmodium falciparum and $P$. vivax growth in vitro, and suggested that these might be attributed to the low bioavailability as well as the kinetic of conversion of ellagic acid to inactive metabolites urolithins.

\section{Adverse effects and reactions/safety}

Pomegranate and its products have a long history of use as food or ethnic medicine without adverse effects, and also it has GRAS (generally recognized as safe) status in the 
USA. The published safety data is limited and no clinical or laboratory adverse events were reported. However, there are some publications on occurrence of allergic reactions when handling or ingestion of pomegranate fruit/seeds due to eliciting a type I hypersensitivity reaction, and thus it is crucial to advise consumers the side effects (McCutcheon et al., 2008).

\section{Conclusion}

Nowadays, it is widely accepted that the beneficial health effects of fruits and vegetables in the prevention of diseases are due to the bioactive compounds they contain.

Based on the explosion of interest in the numerous therapeutic properties over the last decade and in vitro, animal, and clinical trials pomegranate seems to be a promising food with well-defined therapeutic benefits. The epidomiological data suggests that the pomegranate fruit and its associated bioactive compounds such as phenolic acids, flavonoids, and tannins may possess a strong potential as a chemopreventive and possibly as new tools for preventive and possibly therapeutic interventions against various human cancers. This could have a direct practical implication to cancer patients if consumption of fruits like pomegranate can inhibit the process of carcinogenesis. Further studies should focus on the potential clinical usefulness of the agent through issues such as determining the optimal period and route of administration, systemic bioavailability, potent anticancer activity, optimal dosing and toxicity (if any) of the agent and single or combinatorial approach. In addition, the possible use of pomegranate extracts as a therapy or adjunct for prevention and treatment of several disease processes, such as diabetes, cardiovascular disease, atherosclerosis, inflammation, microbial infection, obesity, male infertility, Alzheimer underscores the need for more clinical research. Therefore, ongoing studies should focus on developing novel pomegranate derived products such as ready-to-eat pomegranate seeds, single-strength juices, juice concentrates, seeds in syrup, frozen seeds, and traditional products such as pomegranate pekmez, leather and molasses, to benefit from these constituents throughout a healthy life cycle.

\section{References}

Adams, L.S., Seeram, N.P., Aggarwal, B.B., Takada, Y., Sand, D. \& Heber, D. (2006). Pomegranate Juice, Total Pomegranate Ellagitannins, and Punicalagin Suppress Inflammatory Cellsignaling in Colon Cancer Cells. Journal of Agricultural and Food Chemistry, Vol.54, No.3, pp.980-985, ISSN 0021-8561

Adams, L.S., Zhang, Y., Seeram, N.P., Heber, D. \& Chen, S. (2010). Pomegranate Ellagitannin-derived Compounds Exhibit Antiproiferation and Antiaromatase Activity in Breast Cancer Cells In vitro. Cancer Prevention Research, Vol.3, No.1, pp.108-113, ISSN 1940-6207

Adhami, V.M., Khan, N. \& Mukhtar, H. (2009). Cancer Chemoprevention by Pomegranate: Laboratory and Clinical Evidence. Nutrition and Cancer, Vol.61, No.6, pp.811-815, ISSN 0163-5581

Adhami, V.M., Khan, N. \& Mukhtar, H. (2010). Prevention of Cancer with Pomegranate and Pomegranate Anthocyanins. In: Berries and Cancer Prevention, Stoner, G. \& Seerelam, N.P. (Eds), pp.209-226, ISBN 1441975535, Springer 
Adsule, R.N. \& Patil, N.B. (1995). Pomegranate: In Handbook of Fruit Science and Technology, Salunke, D.K. \& Kadam, S.S. (Eds), pp. 455-464, ISBN 0824796438, Marcel Dekkar, New York

Adsule, R.N., Kotecha, P.M. \& Kadam, S.S. (1992). Preparation of Wine from Pomegranate. Beverage Food World, Vol.19, No.4, pp.13

Afaq, F. (2011). Natural Agents: Cellular and Molecular Mechanisms of Photoprotection. Archives of Biochemistry and Biophysics, Vol.508, No.2, pp.144-151, ISSN 0003-9861

Afaq, F., Saleem, M., Krueger, C.G., Reed, J.D. \& Mukhtar, H. (2005). Anthocyanin- and Hydrolyzable Tannin-rich Pomegranate Fruit Extract Modulates MAPK and NFkappaB Pathways and Inhibits Skin Tumorigenesis in CD-1 mice. International Journal of Cancer, Vol.113, No.3, pp.423-333, ISSN 1097-0215.

Afaq, F., Zaid, M.A., Khan, N., Dreher, M. \& Mukhtar, H. (2009). Protective Effect of Pomegranate-Derived Products on UVB-Mediated Damage in Human Reconstituted Skin. Experimental Dermatology, Vol.18, No.6, pp.553-561, ISSN 16000625

Ahmed, S., Wang, N., Hafeez, B.B., Cheruvu, V.K. \& Haqqi, T.M. (2005). Púnica granatum L. Extracts Inhibits IL-lBeta-induced Expression of Matrix Metalloptoteinases by Inhibiting the Activation of MAP Kinases and NF-kappaB in Human Chondrocytes in vitro. Journal of Nutrition, Vol.135, No.9, pp.2096-2102, ISSN 0022-3166

Akbarpour , V., Hemmati, K., Sharifani, M. \& Sadr, Z.B. (2010). Multivariate Analysis of Physical and Chemical Characteristics in Some Pomegranate (Punica granatum) Cultivars of Iran. Journal of Food, Agriculture and Environment, Vol.8, No.1, pp.244248, ISSN 1459-0255

Akiyama, H., Fujii, K., Yamasaki, O., Oono, T. \& Iwatsuki, K. (2001). Antibacterial Action of Several Tannins Against Staphylococcus aureus. Journal of Antimicrobial Chemotherapy, Vol.48, No.4, pp. 487-491, ISSN 0305-7453

Akpinar-Bayizit, A. (2010). Analysis of Mineral Content in Pomegranate Juice by ICP-OES. Asian Journal of Chemistry, Vol.22, No.8, pp.6542-6546, ISSN 0970-7077

Alam, M.S., Alam, M.A., Ahmad, S., Najmi, A.K., Asif, M. \& Jahangir, T. (2010). Protective Effects of Punica granatum in Experimentally-indoced Gastric Ulcers. Toxicologicy Mechanism and Methods, Vol.20, No.9, pp.572-578, ISSN 1537-6516

Albrecht, M., Jiang, W., Kumi-Diaka, J., Lansky, E.P., Gommersall, L.M., Patel, A., Mansel, R.E., Neeman, I., Geldof, A.A. \& Campbell, M.J. (2004). Pomegranate Extracts Potently Suppress Proliferation, Xenograft Growth, and Invasion of Human Prostate Cancer Cells. Journal of Medicine Food, Vol.7, No.3, pp.274-283, ISSN 1096$620 X$

Al-Maiman, S.A. \& Ahmad, D. (2002). Changes in Physical and Chemical Properties during Pomegranate (Punica granatum L.) Fruit Maturation. Food Chemistry, Vol.76, No.4, pp.437-441, ISSN 0308-8146

Alparslan, M. \&Hayta, M. (2002). Rheological and Sensory Properties of Pekmez (grape molasses) / Tahin (sesame paste) blends. Journal of Food Engineering. Vol.54, No.1, pp.89-93, ISSN 0260-8774

Al-Said, F.A., Opara, L.U. \& Al-Yahyai, R.A. (2009). Physico-chemical and Textural Quality Attributes of Pomegranate Cultivars (Punica granatum L.) Grown in the Sultanate of Oman. Journal of Food Engineering, Vol.90, No.1, pp. 129-134, ISSN 0260-8774 
Altan, A. \& Maskan, M. (2005). Rheological Behavior of Pomegranate (Punica granatum L.) Juice and Concentrate. Journal of Texture Studies, Vol.36, No.1, pp.68-77, ISSN 00224901

Al-Zoreky, N.S. (2009). Antimicrobial Activity of Pomegranate (Punica granatum L.) Fruit Peels. International Journal of Food Microbiology, Vol.134, No.3, pp.244-248, ISSN 0168-1605

Amakura, Y., Okada, M., Tsuji, S. \& Tonogai, Y. (2000). Determination of Phenolic Acids in Fruit Juices by Isocratic Column Liquid Chromatography. Journal of Chromatography A, Vol. 891, No.1, pp.183-188, ISSN 0021-9673.

Amin, A.R.M.R., Kucuk, O., Khuri, F.R. \& Shin, D.M. (2009). Perspectives for Cancer Prevention with Natural Compounds. Journal of Clinical Oncology, Vol.27, No. pp. 2712-2725, ISSN 0732-183X

Aruoma, O. I. (1998). Free Radicals, Oxidative Stress, and Antioxidants in Human Health and Disease. Journal of the American Oil Chemists' Society, Vol.75, No.2, pp.199-212, 0003-021X

Aslam, M.N., Lansky, E.P. \& Varani, J. (2006). Pomegranate as a Cosmeceutical Source: Pomegranate Fractions Promote Proliferation and Procollagen Synthesis and Inhibit Matrix Metalloproteinase-1 Production in Human Skin Cells. Journal of Ethnopharmacology, Vol.103, No.3, pp.311-318, ISSN 0378-8741

Attard, G., Sarker, D., Reid, A., Molife, R., Parker, C. \& de Bono, J.S. (2006). Improving the Outcome of Patients with Castration-resistant Prostate Cancer through Rational Drug Development. British Journal of Cancer, Vol.95, No.7, pp.767-774, ISSN 00070920

Aviram, M., Dornfeld, L., Rosenblat, M., Volkova, N., Kaplan, M., Coleman, R., Hayek, T., Presser, D. \& Fuhrman, B. (2000). Pomegranate Juice Consumption Reduces Oxidative Stress, Atherogenic Modifications to LDL and Platelet Aggregation: Studies in Humans and in Atherosclerotic Apolipoprotein E-deficient mice. The American Journal of Clinical Nutrition, Vol.71, No.5, pp.1062-1076, ISSN 0002-9165.

Bachoual, R., Talmoudi, W., Boussetta, T., Braut, F. \& El-Benna, J. (2011). An Aqueous Pomegranate Peel Extract Inhibits Neutrophil Myeloperoxidase in vitro and Attenuates Lung Inflammation in Mice. Food and Chemical Toxicology, Vol.49, No.6, pp.1224-1228, ISSN 0278-6915

Badenes, M.L., Martínez-Calvo, J. \& Llácer, G. (1998). Analysis of Apricot Germplasm from the European Ecogeographical Group. Euphytica, Vol.102, No.1, pp.93-99, ISSN 0014-2336

Bagri, P., Ali, M., Aeri, V., Bhowmik, M., Sultana, S. (2009). Antidiabetic Effect of Punica granatum Flowers: Effect on Hyperlipidemia, Pancreatic Cells, Lipid Peroxidation and Antioxidant Enzymes in Experimental Diabetes. Food and Chemical Toxicology, Vol.47, No.1-2, pp.50-54, ISSN 0278-6915

Basu, A. \& Penugonda, K. (2009). Pomegranate Juice: A Heart-Healthy Fruit Juice. Nutrition Reviews, Vol.67, No.1, pp.49-56, ISSN 0029-6643

Batta, A.K. \& Rangaswami, S. (1973). Crystalline Chemical Components of Some Vegetable Drugs. Phytochemistry, Vol.12, No.1, pp.214-216, ISSN 0031-9422

Betanzos-Cabrera, G., Guerrero-Solano, J.A., Martínez-Pérez, M.M., Calderón-Ramos, Z.G., Belefant-Miller, H. \& Cancino-Diaz, J.C. (2011). Pomegranate Juice Increases Levels of Paraoxonase1 (PON1) Expression and Enzymatic Activity in Streptozotocin- 
induced Diabetic Mice Fed with a High-fat Diet. Food Research International, Vol.44, No.5, pp.1381-1385, ISSN 0963-9969

Bialonska, D., Kasimsetty, S.G., Khan, S.I. \& Ferreira, D. (2009a). Urolithins, Intestinal Microbial Metabolites of Pomegranate Ellagitannins, Exhibit Potent Antioxidant Activity in a Cell-Based Assay. Journal of Agricultural and Food Chemistry, Vol.57, No.21, pp.10181-10186, ISSN 0021-8561

Bialonska, D., Kasimsetty, S.G., Schrader, K.K. \& Ferreira, D. (2009b). The Effect of Pomegranate (Punica granatum L.) by-products and Ellagitannins on the Growth of Human Gut Bacteria. Journal of Agricultural and Food Chemistry, Vol.57, No.18, pp.8344-8349, ISSN 0021-8561

Boateng, J., Verghese, M., Shackleford, L., Walker, L.T., Khatiwada, J., Ogutu, S., Jones, J., Guyton, M., Asiamah, D., Henderson, F., Grant, L., DeBruce, M., Johnson, A., Washington, S. \& Chawan, C.B. (2007). Selected Fruits Reduce Azoxymethane (AOM)-induced Aberrant Crypt foci (ACF) in Fisher 344 Male Rats. Food and Chemical Toxicology, Vol.45, No.5, pp.725-732, ISSN 0278-6915

Borochov-Neori, H., Judeinstein, S., Tripler, E., Harari, M., Greenberg, A., Shomer, I. \& Holland, D. (2009). Seasonal and Cultivar Variations in Antioxidant and Sensory Quality of Pomegranate (Punica granatum L.) Fruit. Journal of Food Composition and Analysis, Vol.22, No.3, pp.189-195, ISSN 0889-1575

Boukharta, M., Jalbert, G. \& Castonguay, A. (1992). Efficacy of Ellagitannins and Ellagic Acid as Cancer Chemo Preventive Agents. Bulletin of Liaison-Group Polyphenols, Vol.16, pp.245-249, ISSN 0242-8466

Braga, L.C., Leite, A A.M., Xavier, K.G.S., Takahashi, J.A., Bemquerer, M.P., Chartone-Souza, E., Nascimento, A.M.A. (2005). Synergic Interaction between Pomegranate Extract and Antibiotics against Staphylococcus aureus. Canadian Journal of Microbiology, Vol.51, No.7, pp.541-547, ISSN 0008-4166

Chaturvedula, V., Prakash, S. \& Prakash, I. (2011). Bioactive Chemical Constituents from Pomegranate (Punica granatum) Juice, Seed and Peel-A Review. International Journal of Research on Chemistry and Environment, Vol.1, No.1, pp.1-18, ISSN 0306-7319

Chidambara Murthy, K.N., Jayaprakasha, G.K. \& Singh, R.P. (2002). Studies on Antioxidant Activity of Pomegranate (Punica granatum) Peel Extract Using in vivo Models. Journal of Agricultural and Food Chemistry, Vol.50, No.17, pp.4791-4795, ISSN 00218561

Dahham, S.S., Ali, M.N., Tabassum, H. \& Khan, M. (2010). Studies on Antibacterial and Antifungal Activity of Pomegranate (Punica granatum L.). American-Eurasian J. Agric. E Environ. Sci., Vol.9, No.3, pp.273-281, ISSN 1818-6769

Dai, Z., Nair, V., Khan, M. \& Ciolino, H.P. (2010). Pomegranate Extracts Inhibits the Proliferation and Viability of MMTV-Wnt-1 Mouse Mammary Cancer Stem Cells In vitro. Oncology Reports, Vol.24, No.4, pp.1087-1091, ISSN 1021-335X

Das, A.K., Mandal, S.C., Banerjee, S.K., Sinha, S., Das, J., Saha, B.P. \& Pal, M. (1999). Studies on Antidiarrheal Activity of Punica granatum Seed Extract in Rats. Journal of Ethnopharmacology, Vol.68, No.1-3, pp.205-208, ISSN 0378-8741

Dauchet, L., Amouyet, P., \& Dallongeville, J. (2005). Fruit and Vegetable Consumption and Risk of Stroke. A Meta-analysis of Cohort Studies. Neurology, Vol.65, No.8, pp.1193-1197, ISSN 0028-3878

Davidson, M.H., Maki, K.C., Dicklin, M.R., Feinstein, S. B., Witchger, M., Bell, M., McGuire, D.K., Provost, J.C., Liker, H., Aviram, M. (2009). Effects of Consumption of 
Pomegranate Juice on Carotid Intima-Media Thickness in Men and Women at Moderate Risk for Coronary Heart Disease. The American Journal of Cardiology, Vol.104, No.7, pp.936-942, ISSN 0002-9149

de Nigris, F., Williams-Ignarro, S., Botti, C., Sica, V., Ignarro, L.J., Napoli, C. (2006). Pomegranate Juice Reduces Oxidized Low-density Lipoprotein Downregulation of Endothelial Nitric Oxide Synthase in Human Coronary Endothelial Cells. Nitric Oxide, Vol.15, No.3, pp.259-63

Dell'Agli, M., Galli, G.V., Corbett, Y., Taramelli, D., Lucantoni, L., Habluetzel, A., Maschi, O., Caruso, D., Giavarini, F., Romeo, S., Bhattacharya, D. \& Bosisio, E. (2009). Antiplasmodial Activity of Punica granatum L. Fruit Rind. Journal of Ethnopharmacology, Vol.125, No.2, pp. 279-285, ISSN 0378-8741

Demirozu, B., Sokmen, M., Ucak, A., Yilmaz, A. \& Gulderen, S. (2002). Variation of Copper, Iron and Zinc Levels in Pekmez Products. Bulletin of Enviromental Contamination and Toxicology, Vol.69, No.3, pp.330-334, ISSN 1432-0800

Duman, A.D., Ozgen, M., Dayisoylu, K.S., Erbil, N. \& Durgac, C. (2009). Antimicrobial activity of six pomegranate (Punica granatum L.) varieties and their relation to some of their pomological and phytonutrient characteristics. Molecules, Vol.14, No.3, pp.1808-1817, ISSN 1420-3049

Dumas, Y., Dadomo, M., Di Lucca, G. \& Grolier, P. (2003). Effects of Environmental Factors and Agricultural Techniques on Antioxidant Content of Tomatoes. Journal of the Science of Food and Agriculture, Vol.83, No.5, pp.369-382, ISSN 0022-5142

Dutta, B.K., Rahman, I. \& Das, T.K. (1998). Antifungal Activity of Indian Plant Extracts. Mycoses, Vol.41, No.11-12, pp. 535-536, ISSN 0933-7407

Elfalleh, W., Nasri, N., Marzougui, N., Thabti, I., M'Rabet, A., Yahya, Y., Lachiheb, B., Guasmi, F. \& Ferchichi, A. (2009). Physico-chemical Properties and DPPH-ABTS Scavenging Activity of Some Local Pomegranate (Punica granatum) Ecotypes. International Journal of Food Sciences and Nutrition, Vol.60, No.s2, pp.197-210, ISSN 0963-7486

El-Nemr, S.E., Ismail, I.A. \& Ragab, M. (2006). Chemical Composition of Juice and Seeds of Pomegranate Fruit. Die Nahrung, Vol.34, No.7, pp.601-606, ISSN 1613-4133

Endo, E.H., Cortéz, D.A.G., Ueda-Nakamura, T., Nakamura, C.V. \& Filho, B.P.D. (2010). Potent Antifungal Activity of Extracts and Pure Compound Isolated from Pomegranate Peels and Synergism with Fluconazole against Candida albicans. Research in Microbiology, Vol.161, No.7, pp. 534-540, ISSN 0923-2508

Esmaillzadeh, A., Tahbaz, F., Gaieni, I., Alavi-Majd, H. \& Azadbakht, L. (2006). Cholesterollowering Effect ot Concentrated Pomegranate Juice Consumption in Type II Diabetic Patients with Hyperlipidemia. International Journal for Vitamin and Nutrition Reserach, Vol.76, No.3, pp.147-151, ISSN 0300-9831

Evans, M.D., Dizdaroglu, M. \& Cooke, M.S. (2004). Oxidative DNA Damage and Disease: induction, repair and significance. Mutation Research, Vol.567, No.1, pp.1-61, ISSN 0027-5107

Fadavi, A., Barzegar, M., Azizi, M.H. \& Bayat, M. (2005). Physicochemical Composition of Ten Pomegranate Cultivars (Punica granatum L.) Grown in Iran. Food Science and Technology International, Vol.11, No.2, pp. 113-119, ISSN 1082-0132

Fadavi, A., Barzegar, M. \& Azizi, H.M. (2006). Determination of Fatty Acids and Total Lipid Content in Oilseed of 25 Pomegranates Varieties Grown in Iran. Journal of Food Composition and Analysis, Vol.19, No.6-7, pp. 676-680, ISSN 0889-1575 
Faria, A. \& Calhau, C. (2010). Pomegranate in Human Health: An Overview. In: Bioactive Foods in Promoting Health: Fruits and Vegetables, Watson, R.R. \& Preedy V.R.(Eds), pp.551-563, ISBN 9780123746283, Elsevier Science

Faria, A. \& Calhau, C. (2011). The Bioactivity of Pomegranate: Impact on Health and Disease. Critical Reviews in Food Science and Nutrition, Vol.51, No.7, pp.626-634, ISSN 1040-8398

Festa, F., Aglitti, T., Duranti, G., Ricordy, R., Perticone, P. \& Cozzi, R. (2001). Strong Antioxidant Activity of Ellagic Acid in Mammalian Cells in vitro Revealed by the Comet Assay. Anticancer Research, Vol.21, pp. 3903-3908, ISSN 0250-7005

Franco, R., Schoneveld, O., Georgakilas, A. G. \& Panayiotidis, M. I. (2008). Oxidative Stress, DNA Methylation and Carcinogenesis. Cancer Letters, Vol.266, No.1, pp.6-12, ISSN 0304-3835.

George, J., Singh, M., Srivastava, A.K., Bhui, K. \& Shukla, Y. (2011). Synergistic Growth Inhibition of Mouse Skin Tumors by Pomegranate Fruit Extract and Diallyl sulfide: Evidence for Inhibition of Activated MAPKs/NF-kB and Reduced Cell Proliferation. Food and Chemical Toxicology, Vol.49, No.7, pp.1511-1520, ISSN 02786915

Gharzouli, K., Khennouf, S., Amira, S. \& Gharzouli, A. (1999). Effects of Aqueous Extracts from Quercus ilex L. Root Bark, Punica granatum L. Fruit Peel and Artemisia Herbaalba Asso Leaves on Ethanol-induced Gastric Damage in Rats. Phytotheraphy Research, Vol.13, No.1, pp.42-45, ISSN 0951-418X

Gil, M., Tomas-Barberan, I., Hess-Pierce, F., Holcroft, B., D. M., \& Kader, A. (2000). Antioxidant Activity of Pomegranate Juice and its Relationship with Phenolic Composition and Processing. Journal of Agricultural and Food Chemistry, Vol.48, No.10, pp. 4581-4589, ISSN 0021-8561

Gouédard, C., Barouki, R. \& Morel,Y. (2004). Dietary Polyphenols Increase Paraoxonase 1 Gene Expression by an Aryl Hydrocarbon Receptor-dependent Mechanism. Molecular and Cellular Biology, Vol.24, No.12, pp. 5209-5222, ISSN 0270-7306

Gould, S.W., Fielder, M.D., Kelly, A.F., El Sankary, W., \& Naughton, D.P. (2009). Antimicrobial Pomegranate Rind Extracts: Enhancement by $\mathrm{Cu}(\mathrm{II})$ and Vitamin $\mathrm{C}$ Combinations against Clinical Isolates of Pseudomonas aeruginosa. British Journal of Biomedical Science, Vol.66, No.3, pp.129-32, ISSN 0967-4845

Grossmann, M.E., Mizuno, N.K., Schuster, T. \& Cleary, M.P. (2010). Punicic acid, a Fatty Acid from Pomegranate Seed Oil, Inhibits Breast Cancer Cell Proliferation. Cancer Prevention Research, Vol.3, No.1, pp.108-113, ISSN 1940-6207

Gucev, Z.S., Oh, Y., Kelley, K.M. \& Rosenfeld, R.G. (1996). Insulin-like Growth Factor Binding Protein 3 MediatesRetinoic acid- and Transforming Growth Factor beta2induced Growth Inhibition in Human Breast Cancer Cells. Cancer Research, Vol.56, No.7, pp.1545-1550, ISSN 0008-5472

Guo, C., Wei, J., Yang, J., Xu, J., Pang, W. \& Jiang, Y. (2008). Pomegranate Juice is Potentially Better than Apple Juice in Improving Antioxidant Function in Elderly Subjects. Nutrition Research, Vol. 28, No.1, pp. 72-77, ISSN 0271-5317

Gupta, S. \& Mukhtar, H. (2002). Chemoprevention of Skin Cancer: Current Status and Future Prospects. Cancer and Metastasis Reviews, Vol. 21, No.3-4, pp. 363-380,ISSN 0167-7659 
Haidari, M., Ali, M., CasscellsIII, S.W. \& Madjid, M. (2009). Pomegranate (Punica granatum) Purified Polyphenol Extract Inhibits Influenza Virus and has a Synergistic Effect with Oseltamivir. Phytomedicine, Vol.16, No.12, pp.1127-1136, ISSN $0944-7113$

Hajimahmoodi, M., Oveisi, M.R., Sadeghi, N., Jannat, B., Hajibabi, M., Farahani, E., Akrami, M.R. \& Namdar, R. (2008). Antioxidant Properties of Peel and Pulp Hydro Extract in Ten Persian Pomegranate Cultivars. Pakistan Journal of Biological Science, Vol.11, No.12, pp.1600-1604, ISSN 1028-8880

Hamilton, C. A., Miller, W.H., Al-Benna, S., Brosnan, M. J., Drummond, R.D., Mcbride, M.W. \& Dominiczak, A.F. (2004). Strategies to Reduce Oxidative Stress in Cardiovascular Disease. Clinical Science, Vol.106, No.3, pp.219-234, ISSN 0143-5221

Hartman, R.E., Shah, A. \& Fagan, A.M. (2006). Pomegranate Juice Decreases Amyloid Load and Improves Behavior in a Mouse Model of Alzheimer's disease. Neurobiology of Disease, Vol.24, No.3, pp.506-515, ISSN 0969-9961

Heber, D. (2008). Multitargeted Therapy of Cancer by Ellagitannins. Cancer Letters, Vol.269, No.2, pp.262-268, ISSN 0304-3835

Heinlein, C.A. \& Chang, C. (2004). Androgen Receptor in Prostate Cancer. Endocrine Reviews, Vol.25, No.2, pp.276-308, ISSN 0163-769X

Holetz, F.B., Pessini, G.L., Sanches, N.R., Cortez, D.A.G., Nakamura, C.V. \& Filho, B.P.D. (2002), Screening of Some Plants used in the Brazilian Folk Medicine for the Treatment of Infectious Diseases. Memorias do Instituto Oswaldo Cruz, Vol.97, No.7, pp.1027-1031, ISSN 0074-0276

Hong, M.Y., Seeram, N.P. \& Heber, D. (2008). Pomegranate Polyphenols Down-regulate Expression of Androgen-synthesizing Genes in Human Prostate Cancer Cells over Expressing the Androgen Receptor. Journal of Nutritional Biochemistry, Vol.19, No.12, pp. 848-855, ISSN 0955-2863

Hora, J.J., Maydew, E.R., Lansky, E.P. \& Dwivedi, C. (2003). Chemopreventive Effects of Pomegranate Seed Oil on Skin Tumor Development in $\mathrm{CD}_{1}$ Mice. Journal of Medicinal Food, Vol.6, No.3, pp. 157-161, ISSN 1096-620X http://sciyo.com/articles/show/title/wind-power-integrating-wind-turbinegenerators-wtg-s-with-energy-storage

Hu, F.B. (2003). Plant-based Foods and Prevention of Cardiovascular Disease: An overview. The American Journal of Clinical Nutrition, Vol.78, No.3, pp.544-551, ISSN 0002-9165

Huang, T. H. W., Peng, G., Kota, B. P., Li, G. Q., Yamahara, J., Roufogalis, B. D. \& Li, Y. (2005a). Pomegranate Flower Improves Cardiac Lipid Metabolism in a Diabetic Rat Model: Role of Lowering Circulating Lipids. British Journal of Pharmacology, Vol.145, No.6, pp. 767-774, ISSN 1746-5381

Huang, T. H. W., Peng, G., Kota, B. P., Li, G. Q., Yamahara, J., Roufogalis, B. D. \& Li, Y. (2005b). Antidiabetic Action of Punica granatum Flower Extract: Activation of PPAR-gamma and Identification of an Active Component. Toxicology and Applied Pharmacology, Vol.207, No.2, pp.160-169, ISSN 0041-008X

Incedayi, B., Tamer, E.C. \& Copur, U. (2010). A Research on the Composition of Pomegranate Molasses. Journal of Agricultural Faculty of Uludag University, Vol.24, No.2, pp.37-47, ISSN 1301-3165

Jadeja, R.N., Thounaojam, M.C., Patel, D.K., Devkar, R.V., Ramachandran, A.V. (2010). Pomegranate (Punica granatum L.) Juice Supplementation Attenuates Isoproterenolinduced Cardiac Nerosis in Rats. Cardiovascular Toxicology, Vol. 10, No:3, pp. 174180, ISSN: 1559-0259 
Jafri, M. A., Aslam, M., Javed, K. \& Singh, S. (2000). Effect of Punica granatum Linn. (flowers) on Blood Glucose Level in Normal and Alloxan-induced Diabetic Rats. Journal of Ethnopharmacology, Vol.70, No.3, pp.309-314, ISSN 0378-8741

Jahfar, M., Vijayan, K.K. \& Azadi, P. (2003). Studies on a Polysaccharide from the Fruit Rind of Punica granatum. Research Journal of Chemistry and Environment, Vol.7, No.1, pp.43-50, ISSN 0972-0626

Jaiswal, V., DerMarderosian, A. \& Porter, J.R. (2010). Anthocyanins and Polyphenol Oxidase from Dried Arils of Pomegranate (Punica granatum L.). Food Chemistry, Vol.118, No.1, pp. 11-16, ISSN 0308-8146

Jang, A., Srinivasan, P., Lee, N.Y., Song, H.P., Lee, J.W., Lee, M. \& Jo, C.(2008). Comparison of Hypolipidemic Activity of Synthetic Gallic Acid-Linoleic Acid Ester with Mixture of Gallic Acid and Linoleic Acid, Gallic Acid, and Linoleic Acid on Highfat Diet Induced Obesity in C57BL/6 Cr Slc Mice. Chemico-biological Interactions Vol.174, No.2, pp.109-117, ISSN 0009-2797

Jeune, M.A., Kumi-Diaka, J. \& Brown, J. (2005). Anticancer Activities of Pomegranate Extracts and Genistein in Human Breast Cancer Cells. Journal of Medicinal Food, Vol.8, No.4, pp. 469-475, ISSN 1096-620X

Johann, S., Cisalpino, P.S., Watanabe, G.A., Cota, B.B., de Siqueira, E.P., Pizzolatti, M.G., Zani, C.L. \& de Resende, M.A. (2010). Antifungal Activity of Extracts of Some Plants used in Brazilian Traditional Medicine Against the Pathogenic Fungus Paracoccidioides brasiliensis. Pharmaceutical Biology, Vol. 48, No.3, pp. 388-396, ISSN 1388-0209

Johanningsmeier, S.D. \& Harris, G.K. (2011). Pomegranate as a Functional Food and Nutraceutical Source. Annual Review of Food Science and Technology, Vol.2, pp.181-20, ISSN 1941-1413

Jurenka, J.S. (2008). Therapeutic Applications of Pomegranate (Punica granatum L.): A Review. Alternative Medicine Review, Vol.13, No.2, pp. 128-144, ISSN 1089-5159

Kannel, W.B., Neaton, J.D., Wentworth, D. (1986). Overall and Coronary Heart Disease Mortality Rates in Relation to Major Risk Factors in 325,348 Men Screened for the MRFIT. Multiple Risk Factors Intervention Trial. American Heart Journal, Vol.112, No.4, pp:825-836, ISSN 0002-8703

Kaplan, M., Hayek, T., Raz, A., Coleman, R., Dornfeld, L., Vaya, J. \& Aviram, M. (2001). Pomegranate Juice Supplementation to Atherosclerotic Mice Reduces Macrophage Lipid Peroxidation, Cellular Cholesterol Accumulation and Development of Atherosclerosis. Journal of Nutrition, Vol.131, No.8, pp.2082-2089, ISSN 0022-3166

Kasimsetty, S.G., Bialonska, D., Reddy, M.K., Ma, G., Khan, S.I. \& Ferreira, D. (2010). Colon Cancer Chemopreventive Activities of Pomegranate Ellagitannins and Urolithins. Journal of Agricultural and Food Chemistry, Vol.58, No.4, pp.2180-2187, ISSN 00218561

Kawaii, S. \& Lansky, E.P. (2004). Differentiation-promoting Activity of Pomegranate (Punica granatum) Fruit Extracts in HL-60 Human Promyelocytic Leukemia Cells. Journal of Medicinal Food, Vol.7, No1, pp.13-18, ISSN 1096-620X

Kaya, A. \& Sozer, N. (2005). Rheological Behaviour of Sour Pomegranate Juice Concentrates (Punica granatum L.). International Journal of Food Science and Technology, Vol.40, No.2, pp.223-227, ISSN 1365-2621

Khan, N., \& Mukhtar, H. (2010). Cancer Chemoprevention. In: Comprehensive Toxicology, McQueen, C.A. (Ed.) pp.417-431, ISBN 978-0-08-046884-6 Elsevier, UK 
Khan, N., Afaq, F. \& Mukhtar, H. (2008). Cancer Chemoprevention through Dietary Antioxidants: Progress and Promise. Antioxidants Redox Signaling, Vol.10, No. 3, pp.475-510, ISSN 1523-0864

Khan, N., Afaq, F., Kweon, M.H., Kim, K. \& Mukhtar, H. (2007b). Oral Consumption of Pomegranate Fruit Extract Inhibits Growth and Progression of Primary Lung Tumors in Mice. Cancer Research, Vol.67, No.7, pp. 3475-3482, ISSN 0008-5472

Khan, N., Hadi, N., Afaq, F., Syed, D.N., Kweon, M.H. \& Mukhtar, H. (2007a). Pomegranate Fruit Extract inhibits Prosurvival Pathways in Human A549 Lung Carcinoma Cells and Tumor Growth in Athymic Nude Mice. Carcinogenesis, Vol.28, No.1, pp.163173, ISSN 0143-3334

Khan, S.A. (2009). The Role of Pomengranate (Punica granatum L.) in Colon Cancer. Pakistan Journal of Pharmaceutical Science, Vol.22, No.3, pp. 346-348, ISSN 1011-601X

Khateeb, J., Gantman, A., Kreitenberg, A.J., Aviram, M. \& Fuhrman, B. (2010). Paraoxonase 1 (PON1) Expression in Hepatocytes is Upregulated by Pomegranate Polyphenols: A Role for PPAR-gamma Pathway. Atherosclerosis, Vol.208, No.1, pp.119-125, ISSN 0021-9150

Kim, H.S., Ingermann, A.R., Tsubaki, J., Twigg, S.M., Walker, G.E. \& Oh, Y. (2004). Insulinlike Growth Factor-binding Protein 3 induces Caspase-dependent Apoptosis through a Death Receptor-mediated Pathway in MCF-7 Human Breast Cancer Cells. Cancer Research, Vol.64, No.6, pp.2229-2237, ISSN 0008-5472

Kim, N.D., Mehta, R., Yu, W., Neeman, I., Livney, T., Amichay, A., Poirier, D., Nicholls, P., Kirby, A., Jiang, W., Mansel, R., Ramachandran, C., Rabi, T., Kaplan, B. \& Lansky, E.. (2002). Chemopreventive and Adjuvant Therapeutic Potential of Pomegranate (Punica granatum) for Human Breast Cancer. Breast Cancer Research Treatment, Vol.71, No.3, pp.203-217, ISSN 1573-7217

Kohno, H., Suzuki, R., Yasui, Y., Hosokawa, M., Miyashita, K. \& Tanaka, T. (2004b). Pomegranate Seed Oil Rch in Conjugated Linolenic Acid Suppresses Chemically Induced Colon Carcinogenesis in Rats. Cancer Science, Vol.95, No.6, pp.481-486, ISSN 1347-9032

Kohno, H., Yasui, Y., Suzuki, R., Hosokawa, M., Miyashita, K. \& Tanaka, T. (2004a). Dietary Seed Oil Rich in Conjugated Linolenic Acid from Bitter Melon Inhibits Azoxymethane-induced Rat Colon Carcinogenesis through Elevation of Colonic PPAR Gamma Expression and Alteration of Lipid Composition. International Journal of Cancer, Vol.110, No.6, pp.896-901, ISSN 0020-7136

Koyama, S., Cobb, L.J., Mehta, H.H., Seeram, N.P., Heber, D., Pantuck, A.J. \& Cohen, P. (2010). Pomegranate Extract Induces Apoptosis in Human Prostate Cancer Cells by Modulation of the IGF-IGFBP axis. Growth Hormone \& IGF Research, Vol.20, No.1, pp.55-62, ISSN 1096-6374

Kryston, T. B., Georgiev, A. \& Georgakilas, A.G. (2011). Role of Oxidative Stress and DNA Damage in Human Carcinogenesis. Mutation Research, Vol.711, No.1-2, pp.193-201, ISSN 0027-5107

Kulkarni, A. \& Aradhya, S.( 2005). Chemical Changes and Antioxidant Activity in Pomegranate Arils during Fruit Development. Food Chemistry, Vol.90, No.1-2, 319_ 324, ISSN 0308-8146

Lan, J., Lei, F., Hua, L., Wang, Y., Xing, D. \& Du, L. (2009). Transport Behavior of Ellagic Acid of Pomegranate Leaf Tannins and Its Correlation with Total Cholesterol 
Alteration in HepG2 cells. Biomedical Chromatography, Vol.23, No.5, pp.531-536, ISSN 0913-5685

Lansky, E.P. \& Newman, R.A. (2007). Punica granatum (pomegranate) and Its Potential for Prevention and Treatment of Inflammation and Cancer. Journal of Ethnopharmacology, Vol.109, No.2, pp.177-206, ISSN 0378-8741

Lansky, E.P., Harrison, G., Froom, P. \& Jiang, W.G. (2005a). Pomegranate (Punica granatum) Pure Chemicals Show Possible Synergistic Inhibition of Human PC-3 Prostate Cancer Cell Invasion Across Matrigel ${ }^{\mathrm{TM}}$. Investigational New Drugs, Vol.23, No.2, pp.121-122, ISSN 1573-0646

Lansky, E.P., Jiang, W., Mo, H., Bravo, L., Froom, P., Yu, W., Harris, N.M., Neeman, I., Campbell, M.J. (2005b). Possible Synergistic Prostate Cancer Suppression by Anatomically Discrete Pomegranate Fractions. Investigational New Drugs, Vol.23, No.1, pp.11-20, ISSN 1573-0646

Larrosa, M., González-Sarrías, A., Yáñez-Gascón, M.J., Selma, M.V., Azorín-Ortuño, M., Toti, S., Tomás-Barberán, F., Dolara, P. \& Espín, J.C. (2010). Anti-inflammatory Properties of a Pomegranate Extract and its Metabolite Urolithin-A in a Colitis Rat Model and the Effect of Colon Inflammation on Phenolic Metabolism. The Journal of Nutritional Biochemistry, Vol.21, No.8, pp.717-725, ISSN 0955-2863

Larrosa, M., Tomas-Barberan, F.A., Espin, J.C. (2006).The Dietary Hydrolysable Tanin Punicalagin Releases Ellagic Acid that Induces Apoptosis in Human Colon Adenocarcinoma Caco-2 cells by Using the Mitochondrial Pathway. The Journal of Nutritional Biochemistry, Vol.17, No.9, pp. 611-625, ISSN 0955-2863

Lecerf, J.M. (2006) Pasteur Institute - Lille. Functional claims of article 13: Polyphenols in juices. References and Scientific Evidences.

Leckey, L.C., Garige, M., Varatharajalu, R., Gong, M., Nagata, T., Spurney, C.F. \& Lakshman, R.M. (2010). Quercetin and Ethanol Attenuate the Progression of Atherosclerotic Plaques with Concomitant up Regulation of Paraoxonase1 (PON1) Gene Expression and PON1 Activity in LDLR-/- Mice. Alcoholism: Clinical and Experimental Research, Vol.34, No.9, pp.1535-1542, ISSN 1530-0277

Lee, C.J., Chen, L.G., Liang, W.L. \& Wang, C.C. (2010). Anti-inflammatory Effects of Punica granatum Linne in vitro and in vivo. Food Chemistry, Vol.118, No.1-2, pp.315-322, ISSN 0308-8146

Lee, S.I., Kim, B.S., Kim, K.S,. Lee, S., Shin, K.S. \& Lim, J.S. (2008). Immune-suppressive Activity of Punicalagin via Inhibition of NFAT Activation. Biochemical and Biophysical Research Communications, Vol.11, No.371, pp.799-803, ISSN 0006-291X

Lei, F., Zhang, X.N., Wang, W., Xing, D.M., Xie, W.D., Su, H. \& Du, L.J. (2007). Evidence of Anti- obesity Effects of the Pomegranate Leaf Extract in High-fat Diet Induced Obese Mice. International Journal of Obesity, Vol.31, No.6, pp.1023-1029, ISSN 03070565

Li, Y., Guo, C., Yang, J., Wei, J., Xu, J. \& Cheng, S. (2006). Evaluation of Antioxidant Properties of Pomegranate Peel Extract in Comparison with Pomegranate Pulp Extract. Food Chemistry, Vol.96, No.1-2, pp.254-260, ISSN 0308-8146

Li, Y., Qi, Y., Huang, T.H.W., Yamahara, J. \& Roufogalis, B.D. (2008). Pomegranate Flower: A Unique Traditional Antidiabetic Medicine with Dual PPAR- $\alpha /-\gamma$ Activator Properties. Diabetes Obesity and Metabolism, Vol.10, No.1, pp.10-17, ISSN 1463-1326

Liu, J. (1995). Pharmacology of Oleanolic Acid and Ursolic Acid. Journal of Ethnopharmacology, Vol.49, No1, pp.57-68, ISSN 0378-8741 
Longtin, R. (2003). The Pomegranate: Nature's Power Fruit? Journal of the National Cancer Institute, Vol.95, No.5, pp.346-348, ISSN 1460-2105

Machado, T.B., Leal, C.R., Amaral, A.C., Santos, K.R., Silva, M.G. \& Kuster, R.M. (2002). Antimicrobial Ellagitannin of Punica granatum Fruits. Journal of the Brazilian Chemical Society, Vol.13, No.5, pp. 606-610, ISSN 0103-5053

Mackness, B., Mackness, M.I., Durrington, P.N., Arrol, S., Evans, A.E., McMaster, D., Ferrieres, J., Ruidavets, J.B., Williams, N.R. \& Howard, A.N. (2000). Paraoxonase activity in two healthy populations with differing rates of coronary heart disease. European Journal of Clinical Investigation, Vol.30, No.1, pp.4-10, ISSN 0014-2972

Mackness, M. I., Mackness, B. M., \& Durrington, P. N. (2002). Paraoxonase and Coronary Heart Disease. Atherosclerosis Supplements, 3, pp.49-55, ISSN 0021-9150

Madihassan, S. (1984). Outline of the Beginning of Alchemy and Its Antecedents. American Journal of Chinese Medicine, Vol.12, No.1, pp.32-42, ISSN 0192-415X

Maestre, J., Melgarejo, P., Tomas-Barberan, F.A. \& Garcia-Viguera, C. (2000). New food products derived from pomegranate. In: Production, Processing and Marketing of Pomegranate in the Mediterranean Region: Advances in Research and Technology, P. Melgarejo-Moreno, J.J. Martínez-Nicolás and J. Martínez-Tomé, (Eds.), pp. 243-245, ISBN 2-85352-214-8 CIHEAM-IAMZ, Zaragoza.

Malik, A., Afaq, F., Sarfaraz, S., Adhami, V.M., Sved, D.N. \& Mukhtar, H. (2005). Pomegranate Fruit Juice for Chemoprevention and Chemotherapy of Prostate Cancer. Proceedings of the National Academy of Sciences USA, Vol.102, No.40, pp.14813-14818, ISSN 1091-6490

Malik, A., Afaq, S., Shahid, M., Akhtar, K. \& Assiri, A. (2011). Influence of Ellagic acid on Prostate Cancer Cell Proliferetion: A Caspase-Dependent Pathway. Asian Pacific Journal of Tropical Medicine, Vol.4, No.7, pp. 550-555, ISSN 1995-7645

Martin, O.A., Redon, C., Nakamura, A J., Dickey, J.S., Georgakilas, A.G. \& Bonner, W.M. (2011). Systemic DNA Damage Related to Cancer. Cancer Research, Vol.71, No.10, pp.1-5, ISSN 0304-3835

Maskan, A., Kaya, S. \& Maskan, M. (2002). Effect of Concentration and Drying Hot-Air and Microwave Drying. Journal of Food Engineering, Vol. 48, No.2, pp.169-175, ISSN 0260-8774

Mathabe, M.C., Nikolova, R., Lall, V.N. \& Nyazema, N.Z. (2006). Antibacterial Activities of Medicinal Plants used for the Treatment of Diarrhoea in Limpopo Province, South Africa. Journal of Ethnopharmacology, Vol.105, No.2, pp.286-293, ISSN 0378-8741

McCarrell, E.M., Gould, S.W.J., Fielder, M.D., Kelly, A.F., Sankary, W.E. \& Naughton, D.P. (2008). Antimicrobial Activities of Pomegranate Rind Extracts: Enhancement by Addition of Metal Salts and Vitamin C. BMC Complementary and Alternative Medicine, Vol.8, No.1, pp.64-70, ISSN 1472-6882

McCutcheon, A., Udani, J. \& Brown, D.J. (2008). Proprietary Botanical Food Product, Scientific and Clinical Monograph for POM Wonderful ${ }^{\circledR}$ Pomegranate Juice. American Botanical Council. 20p. www.herbalgram.org

Mehta, R. \& Lansky, E.P. (2004). Breast Cancer Chemopreventive Properties of Pomegranate (Punica granatum) Fruit Extracts in a Mouse Mammary Organ Culture. European Journal of Cancer Prevention, Vol.13, No.4, pp.345-355, ISSN 0959-8278

Melgarejo, P. \& Artes, F. (2000). Organic Acids and Sugar Composition of Pomegranate Juice. European Food Research Technology, Vol.4, No.1, pp.30-31, ISSN 1438-2377 
Menezes, S.M., Cordeiro, L.N. \& Viana, G.S. (2006). Púnica granatum (pomegranate) Extract is Active Against Dental Plaque. Journal of herbal pharmacotherapy, Vol.6, No.1, pp.79-92, ISSN 1522-8940

Mertens-Talcott, S.U. \& Percival, S.S. (2005). Ellagic Acid and Quercetin Interact Synergistically with Resveratrol in the Induction of Apoptosis and Cause Transient Cell Cycle Arrest in Human Leukemia Cells. Cancer Letters, Vol. 218, No.2, pp.14151, ISSN 0304-3835

Miguel M.M., Neves, M.A. \& Antunes, M.D. (2010). Pomegranate (Punica granatum L.): A medicinal Plant with Myriad Biological Properties - A Short Review. The Journal of Medicinal Plants Research, Vol. 4, No.25, pp. 2836-2847, ISSN 1996-0875

Miguel, M.G., Dandlen, S. \& Neves, M.A. (2009). Antioxidant Activities of Flower Extract and Pomegranate Juice. Acta Horticulturae (ISHS), Vol.818, pp.389-394, ISSN 05677572

Mirdehghan, S.H. \& Rahemi, M. (2007). Seasonal Changes of Mineral Nutrients and Phenolics in Pomegranate (Punica granatum L.) Fruit. Scientia Horticulturae, Vol.111, No.2, pp.120-127., ISSN 0304-4238

Mirmiran, P., Noori, N., Zavareh, M.B. \& Azizi, F. (2009). Fruit and Vegetable Consumption and Risk Factors for Cardiovascular Disease. Metabolism Clinical and Experimental, Vol.58, No.4, pp.460-468, ISSN 0026-0495

Mooradian, A.D. (2009). Dyslipidemia in Type 2 Diabetes Mellitus. Nature Clinical Practice Endocrinology \& Metabolism, Vol.5, No.3, pp. 150-159, ISSN 1745-8366

Mousavinejad, G., Emam-Djomeh, Z., Rezaei, K., Khodaparast, M.H.H. (2009). Identification and Quantification of Phenolic Compounds and Their Effects on Antioxidant Activity in Pomegranate Juices of Eight Iranian Cultivars. Food Chemistry, Vol.115, No.4, pp.1274-1278, ISSN 0308-8146

Mukhtar, H. \& Ahmad, N. (1999). Cancer chemoprevention: Future Holds in Multiple Agents. Toxicology and Applied Pharmacology, Vol.158, No.3, pp.207-210, ISSN 0041008X

Murthy, K.N.C., Jayaprakasha, G.K. \& Singh, R.P. (2002). Studies on Antioxidant Activity of Pomegranate (Punica granatum) Peel Extract Using in vivo Models. Journal of Agricultural and Food Chemistry, Vol.50, No.17, pp. 4791-4795, ISSN 0021-8561

Murthy, K.N.C., Reddy, K.V. \& Veigas, J.M. (2004). Study on Wound Healing Activity of Punica granatum peel. Journal of Medicinal Food, Vol.7, No.2, pp.256-259, ISSN 1096$620 \mathrm{X}$

Narr Ben, C., Ayed, N. \& Metche, M. (1996). Quantitative Determination of the Polyphenolic Content of Pomegranate Peel. Zeitschrift für Lebensmittel-Untersuchung und Forschung, Vol.203, pp. 374-378, ISSN 1438-2377

Nathan, C. (2006). Neutrophils and Immunity: Challenges and Opportunities. Nature Reviews of Immunology, Vol.6, No.3, pp.173-82, ISSN 1474-1733

Nishikawa, M. (2008). Reactive Oxygen Species in Tumor Metastasis. Cancer Letters, Vol.266, No.1, pp.53-59, ISSN 0304-3835

Noda, Y., Kaneyuka, T., Mori, A. \& Packer, L. (2002). Antioxidant Activities of Pomegranate Fruit Extract and Its Anthocyanidins: Delphinidin, Cyanidin, and Pelargonidin. Journal of Agricultural and Food Chemistry, Vol.50, No.1, pp.166-171, ISSN 0021-8561

Nothlings, U., Schulze, M. B., Weikert, C., Boeing, H., van der Schouw, Y. T., Bamia, C., Benetou, V., Lagiou, P., Krogh, V., Beulens, J. W., Peeters, P. H., Halkjaer, J., Tjonneland, A., Tumino, R., Panico, S., Masala, G., Clavel-Chapelon, F., de, Lauzon 
B., Boutron-Ruault, M. C., Vercambre, M. N., Kaaks, R., Linseisen, J., Overvad, K., Arriola, L., Ardanaz, E., Gonzalez, C. A., Tormo, M. J., Bingham, S., Khaw, K. T., Key, T. J., Vineis, P., Riboli, E., Ferrari, P., Boffetta, P., Bueno-de-Mesquita, H. B., van der, A. DL, Berglund, G., Wirfalt, E., Hallmans, G., Johansson, I., Lund, E., \& Trichopoulo, A. (2008). Intake of vegetables, legumes, and fruit, and risk for allcause, cardiovascular, and cancer mortality in a European diabetic population. The Journal of Nutrition, Vol.138, No.4, pp.775-781, ISSN 0022-3166

Okamoto, T., Akuta, T., Tamura, F., Van Der Vliet, A., \& Akaike, T. (2004).Molecular Mechanism for Activation and Regulation of Matrix Metalloproteinases during Bacterial Infections and Respiratory Inflammation. Biological Chemistry, Vol.385, No.11, pp.997-1006, ISSN 1431-6730

Opara, L.U., Al-ani, M.R. \& Al-Shuaibi, Y.S. (2009). Physico-chemical Properties, Vitamin C Content, and Antimicrobial Properties of Pomegranate Fruit (Punica granatum L.). Food Bioprocess Technology, Vol. 2, No.3. pp.315-321, ISSN 1935-5130

Orak, H.H., Demirci, S., Gumus, T. (2011). Antibacterial and Antifungal Activity of Pomegranate (Punica granatum 1.cv.) Peel. Electronic Journal of Environmental, Agricultural and Food Chemistry, Vol.10, No.3, pp. 1958-1969, ISSN 1579-4377

Oswa, T., Ide, A., Su, J.D., \& Namiki, M. (1987). Inhibiting of Lipid Peroxidation by Ellagic Acid. Journal of Agricultural and Food Chemistry, Vol.35, No.5, pp.808-812, ISSN 00218561

Ou, H.C., Lee, W.J., Lee, S.D., Huang, C.Y., Chiu, T.H., Tsai, K.L., Hsu, W.C., Sheu, W. H.H. ( 2010). Ellagic Acid Protects Endothelial Cells from Oxidized Low-density Lipoprotein-induced Apoptosis by Modulating the PI3K/Akt/eNOS Pathway. Toxicology and Applied Pharmacology, Vol.248, No.2, pp.134-143, ISSN 0041-008X

Ovesná, Z., Vachálková, A., Horváthová, K., \& Tóthová, D. (2004). Pentacyclic Triterpenoic Acids: New Chemoprotective Compounds Minireview. Neoplasma, Vol.51, pp.327333, ISSN 1337-9569

Ozcan, T., Akpinar-Bayizit, A., Yilmaz-Ersan, L., Delikanli. B. \& Yildiz, E. (2011). Bioavailability of Food Polyphenols. International Food Congress-Novel Approaches in Food Industry, İzmir, Turkiye, 26-29 May, 2011

Ozgen, M., Durgac, C., Serce, S. \& Kaya, C. (2008). Chemical and Antioxidant Properties of Pomegranate Cultivars Grown in the Mediterranean Region of Turkey. Food Chemistry, Vol.11. No.3, pp.703-706, ISSN 0308-8146

Ozgul-Yucel, S. (2005). Determination of Conjugated Linolenic Acid Content of Selected Oil Seeds Grown in Turkey. Journal of the American Oil Chemists' Society, Vol.82, No.12, pp.893-897, ISSN 1558-9331

Pacheco-Palencia, L.A., Noratto, G., Hingorani, L., Talcott, S.T. \& Mertens-Talcott, S.U. (2008). Protective Effects of Standardized Pomegranate (Punica granatum L.) Polyphenolic Extract in Ultraviolet-irradiated Human Skin Fibroblasts. Journal of Agricultural and Food Chemistry, Vol.56, No.18, pp.8434-8441, ISSN 0021-8561

Paladini, A.C., Marder, M., Viola, H., Wolfman, C., Wasowski, C. \& Medina, J.H. (1999). Flavonoids and the Central Nervous System: from Forgotten Factors to Potent Anxiolytic Compounds. The Journal of Pharmacy and Pharmacology, Vol.51, No.5, pp.519-526, ISSN 2042-7158

Pande, G. \& Akoh, C.C. (2009). Antioxidant Capacity and Lipid Characterization of Six Georgia- Grown Pomegranate Cultivars. Journal of Agricultural and Food Chemistry, Vol.57, No.20, pp.9427-9436, ISSN 0021-8561 
Panichayupakaranant, P., Tewtrakul, S., Yuenyongsawad, S. (2010). Antibacterial, Antiinflammatory and Anti-allergic Activities of Standardized Pomegranate Rind Extract. Food Chemistry, Vol.123, No.1, pp. 400-403, ISSN 0308-8146

Pantuck, A.J., Leppert, J.T., Zomorodian, N., Aronson, W., Hong, J., Barnard, R.J., Seeram, N., Liker, H., Wang, H., Elashoff, R., Heber, D., Aviram, M., Ignarro, L. \& Belldegrun, A. (2006). Phase II Study of Pomegranate Juice for Men with Rising Prostate-specific Antigen following Surgery or Radiation for Prostate Cancer. Clinical Cancer Research, Vol.12. No.13, pp.4018-4026, ISSN 1557-3265

Parashar, A., Gupta, C., Gupta, S.K. \& Kumar, A. (2009). Antimicrobial Ellagitannin from Pomegranate (Punica granatum) Fruits. International Journal of Fruit Science, Vol. 9, No.3, pp.226-231, ISSN 1553-8621

Park, H.M.., Moon, E., Kim, A.J., Kim, M.H., Lee, S., Lee, J.B., Park, Y.K., Jung, H.S., Kim, Y.B. \& Kim, S.Y. (2010). Extract of Punica granatum Inhibits Skin Photoaging Induced by UVB Irradiation. International Journal of Dermatology, Vol.49, No.3, pp.276-282, ISSN 1365-4632

Perez-Vicente, A., Gil-Izquierdo, A. \& Garcia-Viguera, C. (2002). In vitro Gastrointestinal Digestion Study of Pomegranate Juice Phenolic compounds, Anthocyanins, and Vitamin C. Journal of Agricultural and Food Chemistry, Vol.50, No.8, pp.2308-2312, ISSN 0021-8561

Petti, S. \& Scully, C. (2009). Polyphenols, Oral Health and Disease: A Review. Journal of Dentistry, Vol.37, No.6, pp.413-423, ISSN 0300-5712

Poyrazoglu ,E., Gokmen, V. \& Artik, N. (2002). Organic Acids and Phenolic Compounds in Pomegranates (Punica granatum L.) Grown in Turkey. Journal of Food Composition and Analysis, Vol.15, No.5, pp.567-575, ISSN 0889-1575

Prashanth, D.J., Asha, M.K. \& Amit, A. (2001). Antibacterial Activity of Punica granatum. Fitoterapia, Vol.72, No.2, pp.171-173, ISSN 0367-326X

Pruthi, J.S. \& Saxena, A.K. (1984). Studies on Anardana (dried pomegranate seeds). Journal of Food Science and Technology, Vol.21, No.5, pp.296, ISSN 0022-1155

Raffo, A., La Malfa, G., Fogliano, V., Madani, G. \& Quaglia, G. (2006). Seasonal Variations in Antioxidant Components of Cherry Tomatoes (Lyco-persicon esculentum cv. Naomi F1). Journal of Food Composition and Analysis, Vol.19, No.1, pp.11-19, ISSN 0889-1575

Rahman, M.A., Amin, A.R.M.R., Shin. D.M. (2010). Chemopreventive Potential of Natural Compounds in Head and Neck Cancer. Nutrition and Cancer, Vol.62, No.7, pp.973987, ISSN 0163-5581

Rajah, R., Valentinis, B. \& Cohen, P. (1997). Insulin-like Growth Factor (IGF)-binding protein-3 induces Apoptosis and Mediates the Effects of Transforming Growth Factor-beta1 on Programmed Cell Death through a p53- and IGF-independent Mechanism. Journal of Biological Chemistry, Vol.272, No.18, pp.12181-12188, ISSN 0021-9258

Rakoff-Nahoum, S. (2006). Why Cancer and Inflammation? Yale Journal of Biology and Medicine, Vol.79, No.3-4, pp. 123-130, ISSN 0044-0086

Rettig, M.B., Heber, D., An, J., Seeram, N.D., Rao, J.Y., Liu, H., Klatte, T., Belldegrun, A., Moro, A., Henning, S.M., Mo, D., Aronson, W.J. \& Pantuck, A. (2008). Pomegranate Extract Inhibits Androgen-independent Prostate Cancer Growth through a NuclearFactor-kB-dependent Mechanism. Molecular Cancer Therapeutics, Vol.7, No.9, pp.2662-2671, ISSN 1538-8514 
Richmond, E. \& Viner, J.L. (2003). Chemoprevention of Skin Cancer. Seminars in Oncology Nursing, Vol.19, No.1, pp.62-69. ISSN: 0749-2081

Rosenblat, M., Draganov, D., Watson, C.E., Bisgaier, C.L., La Du, B.N. \& Aviram, M. (2003). Mouse Macrophage Paraoxonase 2 Activity is Increased whereas Cellular Paraoxonase 3Activity is Decreased under Oxidative Stress. Arteriosclerosis, Thrombosis and Vascular Biology, Vol.1, No.23, pp.468-474, ISSN 1079-5642

Rosenblat, M., Volkova, N., Coleman, R. \& Aviram, M. (2006). Pomegranate by Product Administration to Apoiipoprotein e-deficient Mice Attenuates Atherosclerosis Development as a Result on Decreased Macrophage Oxidative Stress and Reduced Cellular Uptake of Oxidized low-density Lipoprotein. Journal of Agricultural and Food Chemistry, Vol.54, No.4, pp.1928-1935, ISSN 0021-8561

Rozenberg, O., Rosenblat, M., Coleman, R., Shih, D.M., \& Aviram, M. (2003). Paraoxonase (PON1) Deficiency is Associated with Increased Macrophage Oxidative Stress Studies in PON1-knockout Mice. Free Radical Biology \& Medicine, Vol.34, No.6, pp.774-784, ISSN 0891-5849

Sadeghi, N., Jannat, B., Oveisi, M.R., Hajimahmoodi, M. \& Photovat, M. (2009). Antioxidant Activity of Iranian Pomegranate (Punica granatum L.) Seed Extracts. Journal of Agriculture, Science and Technology, Vol.11, Supplementary Issue, pp.633-638, ISSN 1680-7073

Salgado, L., Melgarejo, P., Meseguer, I. \& Sánchez, M. (2009). Antimicrobial Activity of Crude Extracts from Pomegranate (Punica granatum L.). Acta Horticulturae, Vol.818, pp.257-264, ISSN 0567-7572

Santos, E.B., Dantas, G.S., Santos, H.B., Diniz, M.F.F.M. \& Sampaio, F.C. (2009). Ethnobotanical Study of Medicinal Plants for Oral Health Problems in the City of Joao Pessoa, Brazil. Brazilian Journal of Pharmacognosy, Vol.19, No.1b, pp.321-324, ISSN 0102-695X

Sartippour, M.R., Seeram, N.P., Rao, J.Y., Moro, A., Harris, D.M., Henning, S.M., Firouzi, A., Rettig, M.B., Aronson, W.J., Pantuck, A.J. \& Heber, D. (2008). Ellagitannin-rich Pomegranate Extract Inhibits Angiogenesis in Prostate Cancer in vitro and in vivo. International Journal of Oncology, Vol. 32, No.2, pp.475-480, ISSN 1791-2423

Sastravaha, G., Yotmicngnit, P., Booncong, P. \& Sangrherapicikul, P. (2003). Adjunctive Periodontal Treatment with Centella asiática and Punica granatum Extracts. A Preliminary Study. Journal of the International Academy of Periodontology, Vol.5, No.2, pp.106-115, ISSN 1466-2094

Schubert, S.Y., Lansky, E.P. \& Necman, I. (1999). Antioxidant and Eicosanoid Enzyme Inhibition Properties of Pomegranate Seed Oil and Fermented Juice Flavonoids. Journal of Ethnopharmacology, Vol.66, No.1, pp.11-17, ISSN 0378-8741

Sedelnikova, O.A., Redon, C.E., Dickey, J.S., Nakamura, A. J., Georgakilas, A.G. \& Bonner, W.M. (2010). Role of Oxidatively Induced DNA Lesions in Human Pathogenesis. Mutation Research, Vol.704, No.1-3, pp.152-159, ISSN 0027-5107

Seeram, N.P., Adams, L.S., Henning, S.M., Niu, Y., Zhang, Y., Nair, M.G. \& Heber, D. (2005). In vitro Antiproliferative, Apoptotic and Antioxidant Activities of Punicalagin, Ellagic acid and a Total Pomegranate Tannin Extract are Enhanced in Combination with Other Polyphenols as Found in Pomegranate Juice. Journal of Nutritional Biochemistry, Vol.16, No.6, pp.360-367, ISSN 0955-2863

Seeram, N.P., Henning, S.M., Zhang, Y., Suchard, M., Li, Z. \& Heber, D. (2006). Pomegranate Juice Ellagitannin Metabolites are Present in Human Plasma and Some Persist in 
Urine for up to 48 hours. Journal of Nutrition, Vol.136, No.10, pp.2481-2485, ISSN 0022-3166

Seppi, A. \& Franciosi, A. (1980). Chemical Composition of Pomegranate Juice (Punica granatum): Amino Acid Contents. Rivista della Società Italiana di Scienze dell'Alimentazione, Vol.9, pp.211-212, ISSN 0391-4887

Sharma, M., Li, L., Celver, J., Killian, C., Kovoor, A. \& Seeram, N.P. (2010). Effects of Fruit Ellagitannin Extracts, Ellagic Acid, and Their Colonic Metabolite, Urolithin A, on Wnt Signaling. Journal of Agricultural and Food Chemistry, Vol.58, No.7, pp. 39653969, ISSN 0021-8561

Shukla, M., Gupta, K., Rasheed, Z., Khan, K.A., \& Haqqi, T.M. (2008). Bioavailable Constituents/metabolites of Pomegranate (Punica granatum L) preferentially Inhibit COX2 Activity ex vivo and IL-1beta-induced PGE2 Production in Human Chondrocytes in vitro. Journal of Inflammation (Lond), Vol.5, No.1, pp.9-19, ISSN 1078-7852

Singh, A. \& Singh, P.K. (2009). An ethnobotanical study of medicinal plants in Chandauli district of Uttar Pradesh, India. Journal of Ethnopharmacology, Vol.121, No.2, pp 324329, ISSN 0378-8741

Singh, D. \& Sethi, V. (2003). Screening of Pomegranate Genotypes for the Preparation of Quality Grade Anardana. Journal of Food Science and Technology, Vol.40, No.2, pp.236-238, ISSN 0022-1155

Singh, D. \& Singh, R.K. (2004). Processed Products of Pomegranate. Natural Product Radiance. Vol.3, No.2, pp.66-68, ISSN 0972-592X

Singh, R.P., Gupta, A.K. \& Bhatia, A.K. (1990). Utilization of Wild Pomegranate in Northwest Himalayas-Status and Problems. In:Proc Nat Semi Production and Marketing of Indigenius Fruits, pp.100-107, New Delhi, India.

Sivarajan, V.V. \& Balachandran, I. (1994). Ayurvedic Drugs and Their Plant Sources. Oxford and IBH Publishing Co. Pvt. Ltd., ISBN 9788120408289, New Delhi, India

Sturgeon, S.R. \& Ronnenberg, A.G. (2010). Pomegranate and Breast Cancer: Possible Mechanisms of Prevention. Nutrition Reviews, Vol.68, No.2, pp.122-128, ISSN 00296643

Su, X., Sangster, M.Y. \& D'Souza, D.H. (2010). In vitro Effects of Pomegranate Juice and Pomegranate Polyphenols on Foodborne Viral Surrogates. Foodborne Pathogens and Disease, Vol.7, No.12, pp.1473-1479, ISSN 1535-3141

Sumner, M.D., Elliott-Eller, M., Weidner, G., Daubenmier, J.J., Chew, M.H., Marlin, R., Raisin, C.J. \& Ornish, D. (2005). Effects of Pomegranate Juice Consumption on Myocardial Perfusion in Patients with Coronary Heart Disease. The American Journal of Cardiology, Vol.96, No.6, pp. 810-814, ISSN 0002-9149

Surh, Y.J. (2003). Cancer Chemoprevention with Dietary Phytochemicals. Nature Reviews Cancer, Vol.3, No.10, pp.768-780, ISSN 1474-175X

Suzuki, R., Noguchi, R., Ota, T., Abe, M., Miyashita, K.. \& Kawada, T. (2001). Cytotoxic Effect of Conjugated Trienoic Fatty Acids on Mouse Tumor and Human Monocytic Leukemia Cells. Lipids, Vol.36, No.5, pp. 477-482, ISSN 0024-4201

Syed, D.N., Afaq, F. \& Mukhtar, H. (2007). Pomegranate Derived Products for Cancer Chemoprevention. Seminars in Cancer Biology, Vol.17, No.5, pp.377-385, ISSN 1044$579 X$

Syed, D.N., Malik, A., Hadi, N., Sarfaraz, S., Afaq, F. \& Mukhtar, H. (2006). Photochemopreventive Effect of Pomegranate Fruit Extract on UVA-mediated Activation 
of Cellular Pathways in Normal Human Epidermal Keratinocytes. Photochemistry Photobiology, Vol.82, No.2, pp.398-405, ISSN 0031-8655

Tayel, A.A. \& El-Tras, W.F. (2009). Anticandidal Activity of Pomegranate Peel Extract Aerosol as an Applicable Sanitizing Method. Mycoses, Vol.52, No.2, pp.117-122, ISSN 0933-7407

Teodoro, T., Zhang, L., Alexander, T., Yue, J., Vranic, M. \& Volchuk, A. (2008). Oleanolic Acid Enhances Insulin Secretion in Pancreatic b-cells. FEBS Letters, Vol.582, No.9, pp.1375-1380, ISSN 0014-5793

Tezcan, F., Gultekin-Ozguven, M., Diken, T., Ozcelik, B. \& Erim, F.B. (2009). Antioxidant Activity and Total Phenolic, Organic Acid and Sugar Content in Commercial Pomegranate Juices. Food Chemistry, Vol.115, No.3, pp.873-877, ISSN 0308-8146

Thresiamma, K.C. \& Kuttan, R. (1996). Inhibition of Liver Fibrosis by Ellagic Acid. Indian Journal of Physiology and Pharmacology, Vol.40, pp.363-366, ISSN 0019-5499

Toi, M., Bando, H., Ramachandran, C., Melnick, S.J., Imai, A., Fife, R.S., Carr, R.E., Oikawa, T. \& Lansky, E.P. (2003) Preliminary Studies on the Anti-angiogenic Potential of Pomegranate Fractions in vitro and in vivo. Angiogenesis Vol.6, No.2, pp. 121-128, ISSN 0969-6970

Toor, R.K., Savage, G.P. \& Lister, C.E. (2006). Seasonal Variations in the Antioxidant Composition of Greenhouse-grown Tomatoes. Journal of Food Composition and Analysis, Vol.19, No.1, pp.1-10, ISSN 0889-1575

Tran, H.N.A., Bae, S-Y., Song, B-H., Lee, B-H., Bae, Y-S., Kim, Y-H., Lansky, E.P. \& Newman, R.A. (2010). Pomegranate (Punica granatum) Seed Linolenic Acid Isomers: Concentration-dependent Modulation of Estrogen Receptor Activity. Endocrine Research, Vol.35, No.1, pp.1-16, ISSN 0743-5800

Tsuyuki, H., Ito, S. \& Nakatsukasa, Y. (1981). Lipids in Pomegranate Seeds. Nihon Daigaku No-Juigakubu Gakujutsu Kenkyu Hokoku, Vol.38, pp.141-148, ISSN 0016-5964

Turk, G., Sonmez, M., Aydin, M., Yuce, A., Gur, S., Yuksel, M., Aksu, E.H. \& Aksoy, H. (2008). Effects of Pomegranate Juice Consumption on Sperm Quality, Spermatogenic Cell Density, Antioxidant Activity and Testosterone Level in Male Rats. Clinical Nutrition, Vol.27, No.2, pp.289-296, ISSN 0261-5614

Van Elswijk, D.A., Schobel, U.P., Lansky, E.P., Irth, H. \& van der Greef, J. (2004). Rapid Dereplication of Estrogenic Compounds in Pomegranate (Punica granatum) using on-line Biochemical Detection Coupled to Mass Spectrometry. Phytochemistry, Vol.65, No.2, pp.233-241, ISSN 0031-9422

Vardin, H. \& Abbasoglu, M. (2004). Nar Eksisi ve Narin Diger Degerlendirme Olanaklari. Geleneksel Gidalar Sempozyumu, Van, Turkiye, 23-24 September

Viuda-Martos, M., Fernández-López, J. \& Pérez-Álvarez, J.A. (2010). Pomegranate and Many Functional Components as Related to Human Health: A Review. Comprehensive Reviews in Food Science and Food Safety, Vol.9, No.6, pp.635-654, ISSN 1541-4337

Voravuthikunchai, S.P. \& Limsuwan, S. (2006). Medicinal Plant Extracts as anti-Escherichia coli O157:H7 Agents and their Effects on Bacterial Cell Aggregation. Journal of Food Protection, Vol.69, No.10, pp.2336-2341, ISSN 0362-028X

Wang, R., Ding, Y., Liu, R., Xiang, L. \& Du, L. (2010). Pomegranate: Constituents, Bioactivities and Pharmacokinetics. In: Fruit, Vegetable and Cereal Science and Biotechnology, da Silva, J.A.T. (Ed), pp. 77-87, ISSN 1752-3419, Global Science Books 
Wang, R., Wang, W., Wang, L., Liu, R., Ding, Y. \& Du, L. (2006). Constituents of the Flowers of Punica granatum. Fitoterapia, Vol. 77, No. 7-8, pp. 534-537, ISSN: 0367-326X

Whitley, A.C., Stoner, G.D., Darby, M.V. \& Walle, T. (2003). Intestinal Epithelial Cell Accumulation of the Cancer Preventive Polyphenol Ellagic acid-Extensive binding to Protein and DNA. Biochemical Pharmacology, Vol.15, No.66, pp.907-915, ISSN 0006-2952

Xu, K.Z., Zhu, C., Kim, M.S., Yamahara, J., Li, Y. (2009). Pomegranate Flower Ameliorates Fatty Liver in an Animal Model of Type 2 Diabetes and Obesity. Journal of Ethnopharmacology, Vol.123, No.2, pp.280-287, ISSN 0378-8741

Yilmaz, C. (2007). Nar. ISBN 978-975-8377-52-2, Hasad Yayıncilik, Istanbul, Turkiye

Yun, J.W. (2010). Possible Anti-obesity Therapeutics from Nature-A review. Phytochemistry, Vol. 71, No.14-15, pp. 1625-1641, ISSN 0031-9422

Zaid, M.A., Afaq, F., Khan, N. \& Mukhtar, H. (2007). Protective Effects of Pomegranate derived Products on UVB-induced DNA Damage, PCNA Expression and MMPs in Human Reconstituted Skin. Journal of Investigative Dermatology, Vol.127, No.1, pp.143-153, ISSN 0022-202X

Zand, R.S., Jenkins, D.J. \& Diamandis, E.P. (2000). Steroid Hormone Activity of Flavonoids and Related Compounds, Breast Cancer Research and Treatment, Vol.62, No1, pp.3549, ISSN 0167-6806

Zarei, M., Azizi, M. \& Bashir-Sadr, Z. (2011). Evaluation of Physicochemical Characteristics of Pomegranate (Punica granatum L.) Fruit during Ripening. Fruits, Vol.66, No.2, pp.121-129, ISSN 0248-129

Zhang, L., Fu, Q. \& Zhang, Y. (2011). Composition of Antociyanins in Pomegranate Flowers and their Antioxidant Activity. Food Chemistry, Vol.127, No.3, pp.1444-1449, ISSN 0308-8146

Ziech, D., Franco, R., Georgakilas, A.G., Georgakila, S., Malamou-Mitsi, V., Schoneveld, O., Pappa, A. \& Panayiotidis, M.I. (2010). The Role of Reactive Oxygen Species and Oxidative Stress in Environmental Carcinogenesis and Biomarker Development. Chemico-Biological Interactions, Vol.188, No.2, pp.334-339, ISSN 0009-2797 


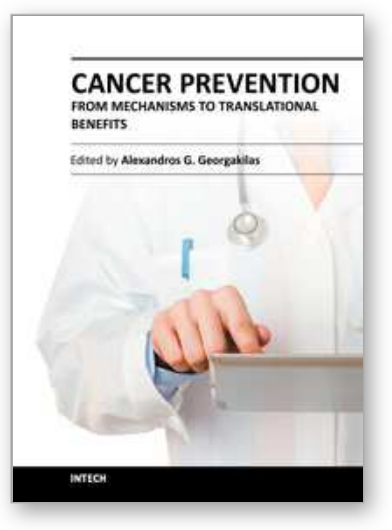

\author{
Cancer Prevention - From Mechanisms to Translational Benefits \\ Edited by Dr. Alexandros G. Georgakilas
}

ISBN 978-953-51-0547-3

Hard cover, 476 pages

Publisher InTech

Published online 20, April, 2012

Published in print edition April, 2012

This unique synthesis of chapters from top experts in their fields targets the unique and significant area of cancer prevention for different types of cancers. Perspective readers are invited to go through novel ideas and current developments in the field of molecular mechanisms for cancer prevention, epidemiological studies, antioxidant therapies and diets, as well as clinical aspects and new advances in prognosis and avoidance of cancer. The primary target audience for the book includes PhD students, researchers, biologists, medical doctors and professionals who are interested in mechanistic studies on cancer prevention and translational benefits for optimized cancer treatment.

\title{
How to reference
}

In order to correctly reference this scholarly work, feel free to copy and paste the following:

Arzu Akpinar-Bayizit, Tulay Ozcan and Lutfiye Yilmaz-Ersan (2012). The Therapeutic Potential of Pomegranate and Its Products for Prevention of Cancer, Cancer Prevention - From Mechanisms to Translational Benefits, Dr. Alexandros G. Georgakilas (Ed.), ISBN: 978-953-51-0547-3, InTech, Available from: http://www.intechopen.com/books/cancer-prevention-from-mechanisms-to-translational-benefits/thetherapeutic-potential-of-pomegranate-and-its-products-for-prevention-of-cancer

\section{INTECH}

open science | open minds

\section{InTech Europe}

University Campus STeP Ri

Slavka Krautzeka 83/A

51000 Rijeka, Croatia

Phone: +385 (51) 770447

Fax: +385 (51) 686166

www.intechopen.com

\section{InTech China}

Unit 405, Office Block, Hotel Equatorial Shanghai

No.65, Yan An Road (West), Shanghai, 200040, China

中国上海市延安西路65号上海国际贵都大饭店办公楼 405 单元

Phone: +86-21-62489820

Fax: $+86-21-62489821$ 
(C) 2012 The Author(s). Licensee IntechOpen. This is an open access article distributed under the terms of the Creative Commons Attribution 3.0 License, which permits unrestricted use, distribution, and reproduction in any medium, provided the original work is properly cited. 